\title{
Synaptically driven phosphorylation of ribosomal protein $\$ 6$ is differentially regulated at active synapses versus dendrites and cell bodies by MAPK and PI3K/ mTOR signaling pathways
}

\author{
Patricia Salgado Pirbhoy, ${ }^{1,2}$ Shannon Farris, ${ }^{1,3,5}$ and Oswald Steward ${ }^{1,2,3,4}$ \\ ${ }^{1}$ Reeve-Irvine Research Center, University of California, Irvine, California 92697, USA; ${ }^{2}$ Department of Neurobiology and Behavior, \\ Center for the Neurobiology of Learning and Memory, University of California, Irvine, California 92697, USA; ${ }^{3}$ Department of Anatomy \\ and Neurobiology; ${ }^{4}$ Department of Neurosurgery, University of California, Irvine, California 92697, USA
}

\begin{abstract}
High-frequency stimulation of the medial perforant path triggers robust phosphorylation of ribosomal protein S6 (rpS6) in activated dendritic domains and granule cell bodies. Here we dissect the signaling pathways responsible for synaptically driven rpS6 phosphorylation in the dentate gyrus using pharmacological agents to inhibit PI3-kinase/mTOR and MAPK/ERK-dependent kinases. Using phospho-specific antibodies for rpS6 at different sites (ser235/236 versus ser240/244), we show that delivery of the PI3-kinase inhibitor, wortmannin, decreased rpS6 phosphorylation throughout the somatodendritic compartment (granule cell layer, inner molecular layer, outer molecular layer), especially in granule cell bodies while sparing phosphorylation at activated synapses (middle molecular layer). In contrast, delivery of U0126, an MEK inhibitor, attenuated rpS6 phosphorylation specifically in the dendritic laminae leaving phosphorylation in the granule cell bodies intact. Delivery of the mTOR inhibitor, rapamycin, abolished activation of rpS6 phosphorylation in granule cell bodies and dendrites, whereas delivery of a selective S6K1 inhibitor, PF4708671, or RSK inhibitor, SLO101-1, attenuated rpS6 phosphorylation throughout the postsynaptic cell. These results reveal that MAPK/ERK-dependent signaling is predominately responsible for the selective induction of rpS6 phosphorylation at active synapses. In contrast, PI3kinase/mTOR-dependent signaling induces rpS6 phosphorylation throughout the somatodendritic compartment but plays a minimal role at active synapses. Collectively, these results suggest a potential mechanism by which PI3-kinase / mTOR and MAPK/ERK pathways regulate translation at specific subcellular compartments in response to synaptic activity.
\end{abstract}

[Supplemental material is available for this article.]

Long-lasting forms of synaptic plasticity are associated with increases in mRNA transcription and de novo protein synthesis, which contribute to enduring forms of synaptic modification including long-term potentiation (LTP) (Nguyen and Kandel 1996; Kandel 2001; Kelleher et al. 2004a; Costa-Mattioli et al. 2009). There is considerable evidence that local translation of mRNAs in dendrites contributes to synaptic modifications that underlie changes in synaptic efficacy, but the signal transduction pathways linking synaptic activity with mRNA translation remain elusive. Recent studies involving perforant path LTP demonstrate that synaptic activation sufficient to trigger LTP induces robust phosphorylation of ribosomal protein $\mathrm{S} 6$ (rpS6) in dentate granule cell bodies (Panja et al. 2009) and selectively in the portion of the dendrite contacted by activated synapses (Pirbhoy et al. 2016).

Phosphorylation of rpS6 is thought to regulate translation initiation of certain mRNAs (Jefferies et al. 1994; Roux et al. 2007; Meyuhas 2008). Recent evidence demonstrates NMDA receptordependent induction of rpS6 phosphorylation following synaptic activation suggesting a mechanistic link with other cellular events that are critical for LTP (Pirbhoy et al. 2016). These findings outline

\footnotetext{
5 Present address: NIH/NIEHS, Research Triangle Park, NC 27709, USA. Corresponding author: osteward@uci.edu
} Article is online at http://www.learnmem.org/cgi/doi/10.1101//m.044974.117. a potential mechanism by which NMDA receptor-dependent activation of rpS6 phosphorylation modulates mRNA translation at postsynaptic cell bodies and synapses.

Although high-frequency activation of synapses robustly triggers rpS6 phosphorylation, the signal transduction pathways linking NMDA receptor activation and rpS6 phosphorylation are poorly understood. Also, unknown is whether different signal transduction pathways mediate rpS6 phosphorylation at activated synapses versus distant cell bodies. Two candidate pathways downstream from the NMDA receptor are phosphoinositide 3-kinase (PI3-kinase) (Gong et al. 2006) and mitogen-activated protein kinases/extracellular signal-regulated kinases (MAPK/ERK) (Jin et al. 2013; Wang and Peng 2016). Previous studies in nonneuronal cells indicate that phosphorylation of rpS6 can be triggered by either pathway (Jefferies et al. 1994; Roux et al. 2007). Studies in hippocampal slices have provided evidence that PI3-kinase and mammalian target of rapamycin (mTOR) (Tang

(C) 2017 Pirbhoy et al. This article is distributed exclusively by Cold Spring Harbor Laboratory Press for the first 12 months after the full-issue publication date (see http://learnmem.cshlp.org/site/misc/terms.xhtml). After 12 months, it is available under a Creative Commons License (AttributionNonCommercial 4.0 International), as described at http://creativecommons. org/licenses/by-nc/4.0/. 
et al. 2002) and MAPK/ERK (Kelleher et al. 2004b) play critical roles in LTP. LTP induction triggers phosphorylation of mTOR substrates, which is accompanied by increases in protein synthesis in hippocampal slices (Kelleher et al. 2004b; Tsokas et al. 2005) and also triggers activation of MAPK/ERK substrates, and translation-related factors (Kelleher et al. 2004b). The implicated role of MAPK/ERK in translational control has prompted the hypothesis that PI3K/mTOR and the MAPK/ERK signaling pathways cooperate to coordinate regulation of cap-dependent and $5^{\prime}$ terminal oligopyrimidine (5'TOP) mRNA translation (Wang et al. 2001b; Kelleher et al. 2004b; Shahbazian et al. 2006).

Here we test the hypothesis that signal transduction pathways differentially regulate phosphorylation of $\mathrm{rpS} 6$ to control translation initiation in different subcellular compartments. Our approach uses the model system in which rpS6 phosphorylation is induced by stimulating the medial perforant path (MPP) projections to dentate granule cells at high-frequencies sufficient to induce LTP (Pirbhoy et al. 2016). To test the role of each signaling pathway, pharmacological inhibitors were locally infused into the dentate gyrus during MPP stimulation. Phosphorylation of rpS6 at different serine residues was assessed by immunostaining using phospho-specific antibodies that recognize phosphorylation of rpS6 at ser235/236, and ser240/244. Phosphorylation of rpS6 at ser240/244 is thought to be via mTOR-dependent signaling, while phosphorylation of ser235/236 can be regulated by multiple signaling pathways including MAPK/ERK, protein kinase C (PKC) (Gangarossa and Valjent 2012), PKA (Biever et al. 2015), and mTOR (Roux et al. 2007; Gobert et al. 2008).

We show site-specific regulation of rpS6 phosphorylation by MAPK/ERK and PI3-kinase signaling pathways. Local infusion of the PI3-kinase inhibitor, wortmannin, decreases rpS6 phosphorylation specifically at ser235/236 throughout the postsynaptic cell while preserving activation in the region of activated synapses. In contrast, local infusion of U0126, an MEK inhibitor, decreases rpS6 phosphorylation specifically in the activated dendritic lamina sparing activation in granule cell bodies. Local delivery of the mTOR inhibitor, rapamycin, the S6K1 inhibitor, PF4708671, and the RSK inhibitor, SL0101-1, attenuated rpS6 phosphorylation in both granule cell bodies and dendrites. These results indicate that MAPK/ERK signaling is primarily responsible for inducing phosphorylation of rpS6 at activated synapses, whereas PI3-kinase/mTOR-dependent signaling induces rpS6 phosphorylation throughout the postsynaptic cell.

\section{Results}

\section{Phosphorylation of rpS6 is differentially regulated in granule cell bodies and dendrites}

As documented in our previous study (Pirbhoy et al. 2016), repeated stimulation of the medial perforant path (MPP) with brief highfrequency trains (as used to induce LTP) induces robust increases in immunostaining for rpS6 phosphorylation at ser235/236 in the activated dendritic lamina and the cell bodies of dentate granule cells. This effect can be seen in the figures of the present manuscript in areas distant from the site of drug infusion, which represents the control for the drug infusion sites (see, for example, Fig. 2A,B; compare with control nonstimulated side in Fig. 2G,H). Increases in the activated dendritic lamina are evident as a band of increased immunostaining in the middle molecular layer of the dentate gyrus, which is the site of termination of the MPP. The pattern is different for sections immunostained with the antibody detecting phosphorylation of rpS6 at ser240/244 in that increases in immunostaining are seen in granule cell bodies and throughout the dendritic laminae without an evident band in the zone of activated MPP synapses (see, for example, Fig. 2I,J; compare with control nonstimulated side in Fig. 2O,P).

Previous studies report that induction of perforant path LTP activates both PI3-kinase (Kelly and Lynch 2000) and MAPK/ERK (Chotiner et al. 2010). There is also evidence that both mTORand MAPK/ERK-dependent signaling pathways regulate phosphorylation of rpS6 at ser235/236, while phosphorylation at ser240/ 244 is predominately mTOR-dependent (Roux et al. 2007). Therefore, we begin by assessing the contribution of PI3-kinase signaling to rpS6 phosphorylation.

\section{Local infusion of the PI3-kinase inhibitor, wortmannin, blocks somatodendritic induction of rpS6 phosphorylation sparing rpS6 phosphorylation at activated synapses}

To assess the role of Akt/mTOR in mediating induction of rpS6 phosphorylation, we locally infused the PI3-kinase inhibitor, wortmannin, into the dorsal blade of the dentate gyrus before HFS. The approach was the same as in our previous studies in which a recording micropipette containing the pharmacological agent was positioned in the dorsal blade of the dentate gyrus. The tip of the micropipette is broken to a diameter of $\sim 40-100 \mu \mathrm{m}$ resulting in local diffusion of the drug within an area several millimeters in diameter (Steward and Worley 2001). The micropipette is left in place for the duration of the experiment, so drug concentrations remain constant in the sphere of diffusion.

It is important to note several strengths and caveats of the approach involving local diffusion from a micropipette. First, the local blockade in a defined area leaves other parts of the hippocampus to serve as internal controls. Areas distant from the drug infusion on the ipsilateral side reveal the consequences of HFS; the contralateral hippocampus serves as a nonactivated intra-animal control. Second, delivering drugs by diffusion from the micropipette eliminates potential problems associated with injecting volumes of fluid, which can cause tissue damage. Third, tissue concentrations of the drugs are much lower than the concentrations in the micropipette, and concentration decreases with distance from the micropipette tip based on laws of diffusion. A caveat, however, is that it is not possible to determine the exact drug concentration after infusion in vivo. Finally, it should be noted that our numerous animals prepared for our previous study document that electrode placement alone does not cause any local disruption of rpS6 phosphorylation (Pirbhoy et al. 2016).

In all experiments, physiological consequences of drug infusion were assessed. Positive-going field excitatory postsynaptic potentials (EPSPs) and population spikes were initially recorded using a saline-filled micropipette, and then the saline electrode was replaced with one filled with the relevant drug. The graphs in Figure $1 \mathrm{~A}$ and $\mathrm{B}$ illustrate the paradigm for experiments involving wortmannin infusion. Following replacement of the saline-filled micropipette with the wortmannin-filled micropipette, population spike amplitude was $83.02 \pm 9.789 \%$ of baseline (mean \pm SEM, $N=8$ ) and EPSP slope was $86.05 \pm 3.17 \%$ of baseline (Fig. $1 \mathrm{~B}, N=8)$. In one case, the population spike decreased to 0.66 $\mathrm{mV}$, which is below our arbitrary cutoff of $1.5 \mathrm{mV}$ for studies involving LTP, so physiological data for population spike amplitude was analyzed with and without this case. The population spike amplitude with the excluded case was $85.59 \pm 10.91 \%$ of baseline (Fig. $1 \mathrm{~A}, N=7)$ and EPSP slope was $87.27 \pm 3.38 \%$ of baseline $(N=7)$.

Following delivery of 30 high-frequency trains (our standard paradigm for inducing perforant path LTP), population spike amplitude and EPSP slope increased as is observed in control experiments with saline-filled microelectrodes (Fig. 1A,B; percent change for wortmannin (amplitude): $249.3 \pm 68.28 \%, N=7$; saline: $139.5 \pm 27.28 \%, N=6$; percent change for wortmannin (slope): $47.22 \pm 2.34 \%, N=8$; saline: $28.32 \pm 3.34 \%, N=6$ ). 
Immunostaining using the phospho-specific antibody that detects phosphorylation of rpS6 at ser235/236 confirmed robust increases in immunostaining of granule cell bodies with a band of increased immunostaining in the dendritic lamina in areas distant from the site of infusion (Fig. 2A,B; compare with the contralateral control in Fig. 2G,H). Strikingly, in the wortmannin infusion area, the increase in immunostaining for rpS6 phosphorylation in granule cell bodies was blocked whereas the band of in-
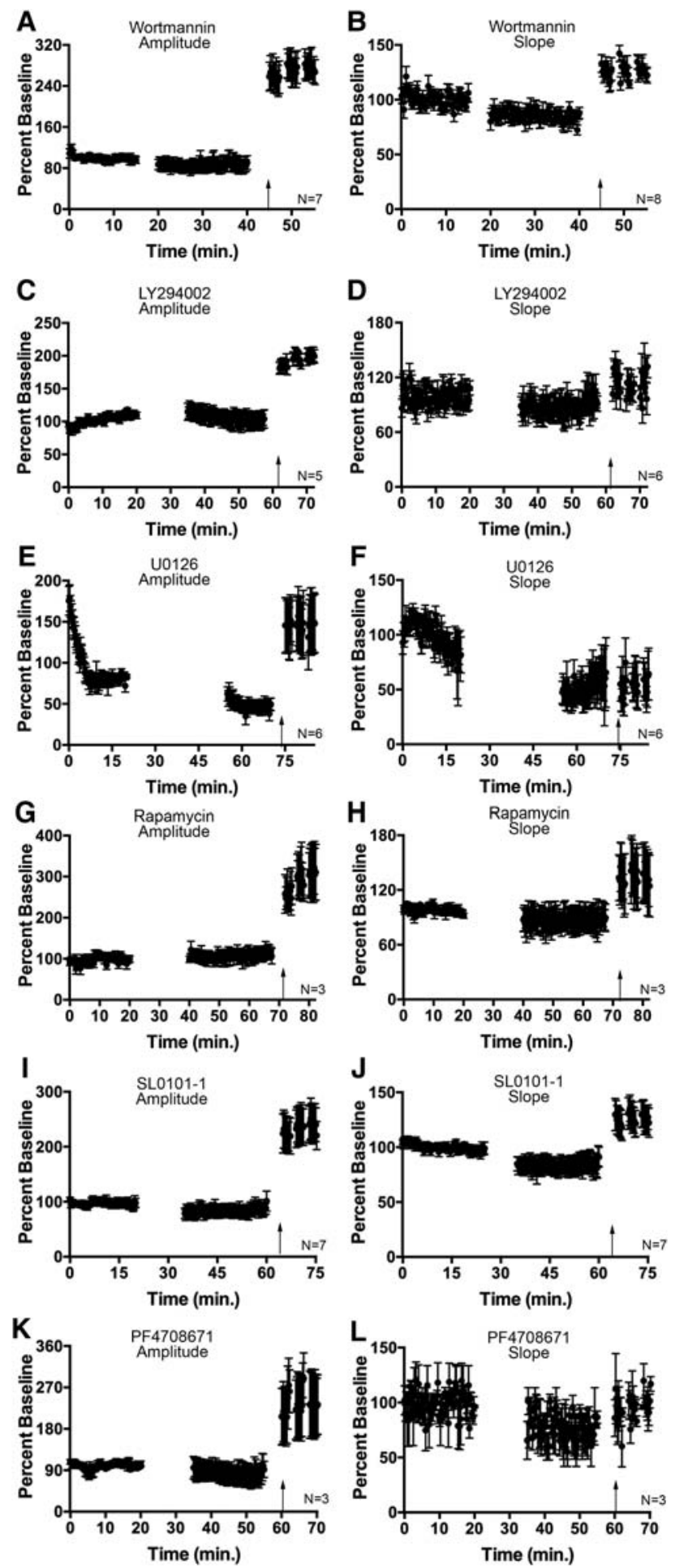

creased immunostaining in the dendritic lamina was preserved (Fig. 2E,F).

To quantify effects of wortmannin blockade, levels of immunostaining were assessed by measuring average optical density (OD) across the dorsal blade of the dentate gyrus. OD values in the region of the blockade (labeled "Infusion" on the plot in Fig. 2C) were compared with distant areas outside the sphere of inhibition (labeled "Distant" on the plot in Fig. 2C) and to the contralateral, nonstimulated side (Contra). The plot in Figure 2C shows average $\mathrm{OD}$ values across the dorsal blade of the dentate gyrus from the granule cell layer to the outer molecular layer $(\sim 300 \mu \mathrm{m})$. To provide a statistical analysis of the blockade (Fig. $2 \mathrm{D})$, average OD values at four measuring sites were compared $(N=8$ rats): the granule cell layer (GCL), the inner molecular (IML), the peak immunostaining in the middle molecular layer (MML), and a distance of $280 \mu \mathrm{m}$ from the GCL to represent the outer molecular layer (OML) (denoted by arrows in Fig. 2C,K). Quantitative comparisons of levels of OD values for distant, infusion, and contralateral sections in the four measuring sites by twoway ANOVA yielded an overall $F_{(6,84)}=8.44, P<0.0001$ (Fig. $2 \mathrm{D}, N$ $=8$ ). Post hoc analysis with Bonferroni's multiple comparisons tests revealed that OD values in areas distant from the wortmannin infusion were statistically different than in the infusion area and contralateral sections in all regions. Notably, OD values in the MML, within the infusion area was also significantly different than on the contralateral side (Fig. 2D, for details on statistics, see figure legends; two-way ANOVA, $P<0.05)$. Collectively, these data suggest the surprising conclusion that PI3-kinase activation is critical for rpS6 phosphorylation at ser235/236 throughout the somatodendritic compartment (GCL, IML, OML) but has a minimal role in the local activation of $\mathrm{rpS} 6$ phosphorylation in the portion of the dendrite contacted by active synapses (MML).

Figure 1. Average population spike amplitude and EPSP slope following local delivery of pharmacological agents into the dentate gyrus. $(A)$ Average population spike amplitude and EPSP slope $(B)$ following local delivery of the PI3-kinase inhibitor, wortmannin. Saline baseline was recorded for $15 \mathrm{~min}$. The saline-filled micropipette was replaced for a wortmannin-filled micropipette and baseline was recorded for $20 \mathrm{~min}$, followed by delivery of 30 trains of HFS (time of HFS delivery denoted by arrow). (C) Average population spike amplitude and EPSP slope (D) following delivery of the reversible PI3-kinase inhibitor, LY294002. Saline baseline was recorded for $20 \mathrm{~min}$. Following replacement of the saline-filled micropipette with the LY294002-filled micropipette, no test pulses were delivered for $15 \mathrm{~min}$; baseline was then recorded for $20 \mathrm{~min}$, followed by delivery of 30 trains of HFS (time of HFS delivery denoted by arrow). $(E)$ Average population spike amplitude and EPSP slope $(F)$ following delivery of the MEK inhibitor, U0126. Baseline responses were recorded for 20 min via the Hamilton micropipette before injection, then injection of U0126 was administered within a 5-min time window. No test pulses were delivered for $35 \mathrm{~min}$ following injection; baseline was then recorded for 10 min, followed by delivery of 30 trains of HFS (time of HFS delivery denoted by arrow). (G) Average population spike amplitude and EPSP slope $(H)$ following local delivery of the mTOR inhibitor, rapamycin. Saline baseline was recorded for $20 \mathrm{~min}$. Following replacement of the saline-filled micropipette for a rapamycin-filled micropipette, no test pulses were delivered for $20 \mathrm{~min}$; baseline was then recorded for 25 min, followed by delivery of 30 trains of HFS (time of HFS delivery denoted by arrow). (I) Average population spike amplitude and EPSP slope $(J)$ following local delivery of the RSK inhibitor, SL0101-1. Saline baseline was recorded for $20 \mathrm{~min}$. Following replacement of the salinefilled micropipette for an SL0101-1-filled micropipette, no test pulses were delivered for $15 \mathrm{~min}$; baseline was then recorded for $25 \mathrm{~min}$, followed by delivery of 30 trains of HFS (time of HFS delivery denoted by arrow). ( $K$ ) Average population spike amplitude and EPSP slope (L) following local delivery of the S6K1 inhibitor, PF4708671. Saline baseline was recorded for $20 \mathrm{~min}$. Following replacement of the saline-filled micropipette for a PF4708671-filled micropipette, no test pulses were delivered for $15 \mathrm{~min}$; baseline was then recorded for $20 \mathrm{~min}$, followed by delivery of 30 trains of HFS (time of HFS delivery denoted by arrow). 

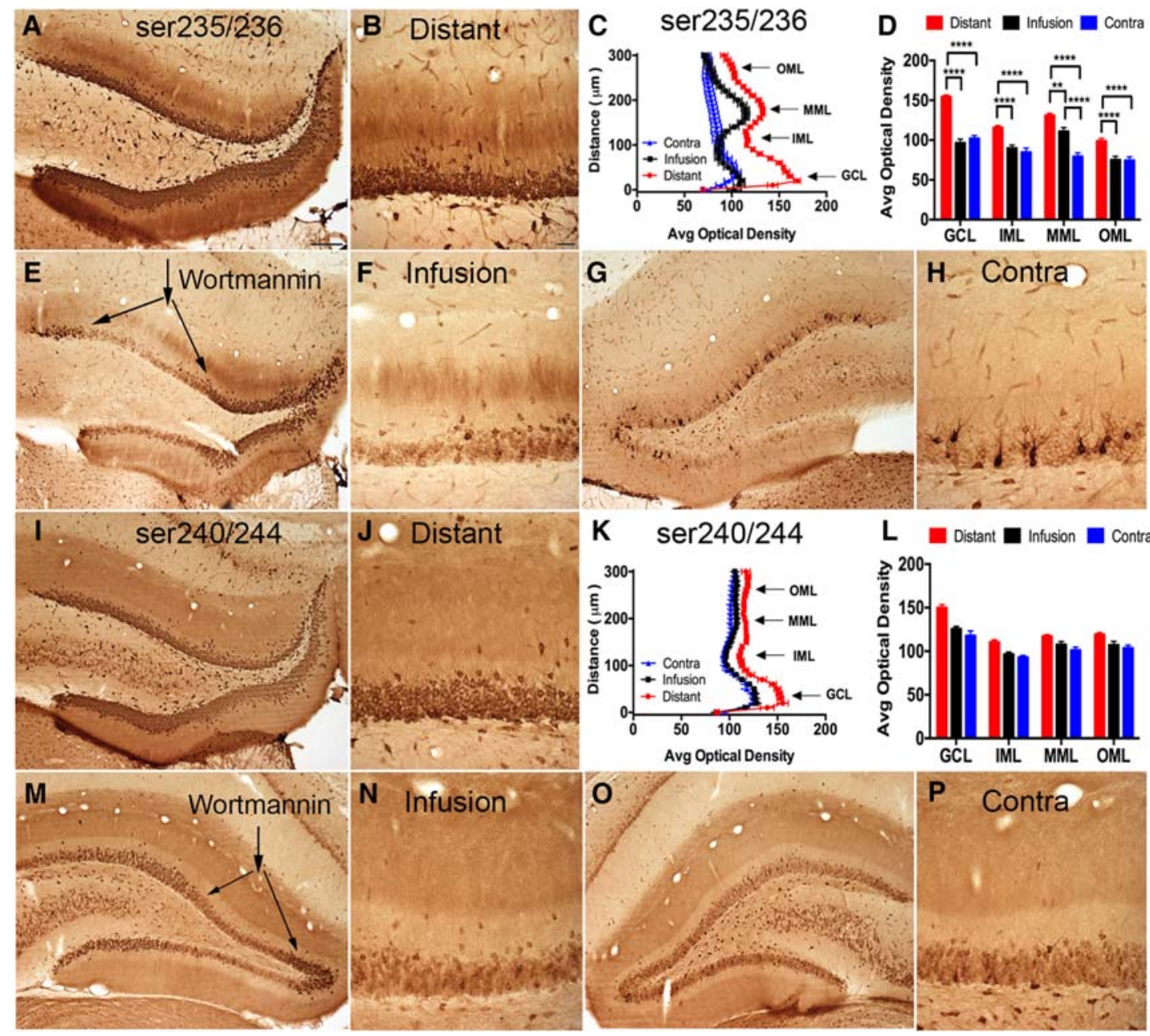

Figure 2. Local infusion of the PI3-kinase inhibitor, wortmannin, blocks somatodendritic phosphorylation of rpS6 but not in the zone of activated synapses. (A) Immunostaining for p-ser235/236 ipsilateral to stimulation in a section distant from the infusion area. (B) High-magnification image of $A$. (C) Quantification of average OD across the dorsal blade of the dentate gyrus in ipsilateral sections distant from the infusion area ("Distant"), ipsilateral sections within the infusion area ("Infusion"), and contralateral, nonstimulated sections ("Contra"). (D) Statistical assessment at four sites along the dentate gyrus (denoted by the arrows), GCL, IML, MML, OML (ser235/236, $N=8$ ), error bars represent SEM. Statistical assessment by two-way ANOVA revealed a significant interaction $\left(F_{(6,84)}=8.44, P<0.0001\right)$, a significant main effect of treatment $\left(F_{(2,84)}=114.30, P<0.0001\right)$, and a significant main effect of region $\left(F_{(3,84)}\right.$ $=42.36, P<0.0001)$. Post hoc analysis with Bonferroni's multiple comparisons tests revealed that distant sections were statistically different than sections within the infusion area and contralateral sections in all regions. Notably, in the MML, sections within the infusion area were significantly different than contralateral sections (two-way ANOVA, $P<0.05$ ). (E) Immunostaining of $p$-ser235/236 ipsilateral to the stimulation in a section within the infusion area in the presence of wortmannin (arrows denote infusion area). (F) High-magnification image of $E$. Note the decrease in rpS6 phosphorylation specifically in the GCL and nonactivated dendritic regions (IML and OML) and sparing of rpS6 phosphorylation in the zone of activated synapses (MML). (G) Immunostaining of p-ser235/236 contralateral to the stimulation. (H) High-magnification image of $G$. (I) Immunostaining of p-ser240/244 in a section distant from the infusion area. (/) High-magnification image of $I$. (K) Quantification of average OD across the dorsal blade of the dentate gyrus in distant, infusion, and contralateral sections. (L) Statistical assessment at four sites along the dentate gyrus (denoted by the arrows), GCL, IML, MML, OML (ser240/244, $N=5$ ), error bars represent SEM. Statistical assessment by two-way ANOVA revealed a main effect of treatment $\left(F_{(2,48)}=41.26, P<0.0001\right)$ and a main effect of region $\left(F_{(3,48)}=\right.$ 48.69, $P<0.0001)$, but no significant interaction $\left(F_{(6,48)}=1.72, P=0.137\right) .(M)$ Immunostaining of $p$-ser240/244 ipsilateral to stimulation in a section within the infusion area in the presence of wortmannin (arrows denote infusion area). ( $N$ ) High-magnification image of $M$. (O) Immunostaining of p-ser240/244 contralateral to the stimulation. $(P)$ High-magnification image of $O$. Scale bars: $A, 200 \mu \mathrm{m} ; B, 50 \mu \mathrm{m}$.

Different results were seen using the antibody for rpS6 phosphorylation at ser240/244 (p-ser240/244). In distant areas from the wortmannin infusion, there were increases in immunostaining throughout the somatodendritic compartment but without a band of increased level of labeling in the zone of activated synapses (cf. Fig. 2I,J and Fig. 2A,B). Although qualitatively evident in all cases, the overall two-way ANOVA of OD values ( $N=5$ animals) did not reach statistical significance $\left(F_{(6,48)}=1.72, P=0.1377\right)$. In the wortmannin infusion area (Fig. $2 \mathrm{M}, \mathrm{N}$ ), increases in immunostaining in both cell bodies and dendrites were blocked; indeed, immunostaining the granule cell layer and the molecular layer was indistinguishable from the contralateral control (Fig. 2O,P) and for quantification, see Figure $2 \mathrm{~K}$ and $\mathrm{L}$.

To determine whether similar results would be seen with a different PI3-kinase inhibitor that acts via a different mechanism, LY294002 was locally infused. Wortmannin is an irreversible, cellpermeable fungal metabolite that potently inhibits PI3-kinase with an $\mathrm{IC}_{50}$ of $5 \mathrm{nM}$ (Arcaro and Wymann 1993). LY294002 is a reversible PI3-kinase inhibitor that acts on the ATP binding site of PI3-kinase (Vlahos et al. 1994). Both wortmannin and LY294002 have been reported to disrupt LTP in hippocampal slices (Sanna et al. 2002). 


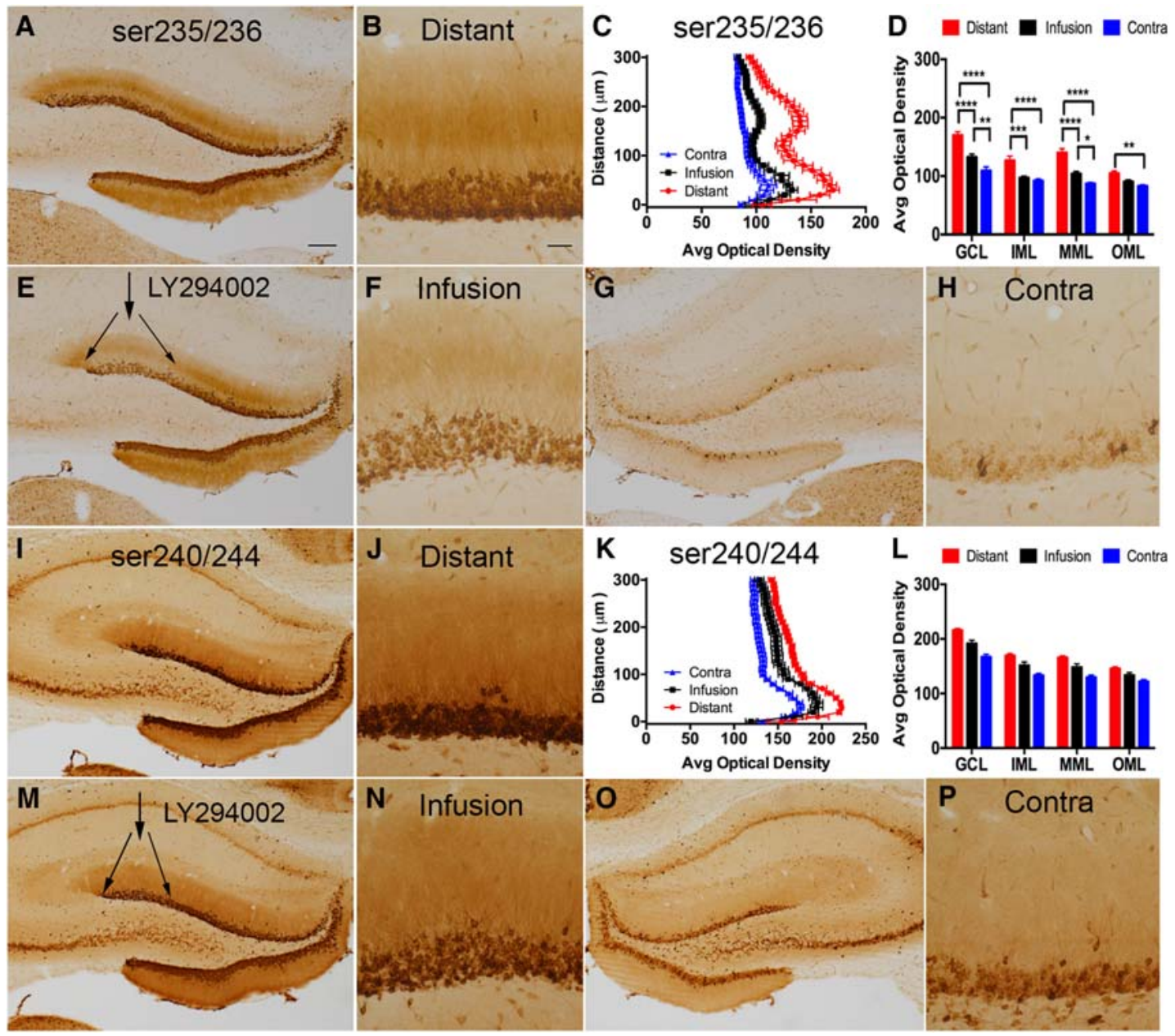

Figure 3. Local infusion of the reversible PI3-kinase inhibitor, LY294002, attenuates phosphorylation of rpS6. (A) Immunostaining for p-ser235/236 ipsilateral to stimulation in a section distant from the infusion area. (B) High-magnification image of $A$. (C) Quantification of average OD across the dorsal blade of the dentate gyrus in ipsilateral sections distant from the infusion area, ipsilateral sections within the infusion area, and contralateral, nonstimulated sections. (D) Statistical assessment at four sites along the dentate gyrus, GCL, IML, MML, OML (ser235/236, $N=6$ ), error bars represent SEM. Statistical assessment by two-way ANOVA revealed a significant interaction $\left(F_{(6,60)}=3.67, P=0.0036\right)$, a significant main effect of treatment $\left(F_{(2,60)}=84.34, P<\right.$ $0.0001)$, and a significant main effect of region $\left(F_{(3,60)}=46.65, P<0.0001\right)$. Post hoc analysis with Bonferroni's multiple comparisons tests revealed that distant sections were statistically different than sections within the infusion area and contralateral sections in the GCL, IML, and MML. Distant sections were also significantly different than contralateral sections in the OML. Notably, sections within the infusion area were also statistically different than contralateral sections in the GCL and MML (two-way ANOVA, $P<0.05$ ). (E) Immunostaining of $p$-ser235/236 ipsilateral to the stimulation in a section within the infusion area in the presence of LY294002 (arrows denote infusion area). (F) High-magnification image of $E$. Note the reduction in rpS6 phosphorylation in the GCL and throughout the molecular layer of the dentate gyrus. The distinct band of rpS6 phosphorylation remains in sections within the infusion area. (G) Immunostaining of p-ser235/236 contralateral to the stimulation. (H) High-magnification image of $G$. (I) Immunostaining of p-ser240/244 in a section distant from the infusion area. (/) High-magnification image of $I$. (K) Quantification of average OD across the dorsal blade of the dentate gyrus in ipsilateral sections distant from the infusion area, ipsilateral sections within the infusion area, and contralateral sections. (L) Statistical assessment at four sites along the dentate gyrus, GCL, IML, MML, OML (ser240/244, $N=6$ ), error bars represent SEM. Statistical assessment by two-way ANOVA revealed a main effect of treatment $\left(F_{(2,60)}=67.23, P<0.0001\right)$ and a main effect of region $\left(F_{(3,60)}=94.19, P<0.0001\right)$, but no significant interaction $\left(F_{(6,60)}=1.37, P\right.$ $=0.2402$ ). $(M)$ Immunostaining of p-ser240/244 ipsilateral to stimulation within the infusion area in the presence of LY294002 (arrows denote infusion area). (N) High-magnification image of $M$. (O) Immunostaining of p-ser240/244 contralateral to the stimulation. $(P)$ High-magnification image of $O$. Scale bars: $A, 200 \mu \mathrm{m} ; B, 50 \mu \mathrm{m}$.

LY294002 was locally infused into the dentate gyrus as above; following replacement of the saline-filled micropipette with the LY294002-filled micropipette, the population spike amplitude was $91.55 \pm 17.44 \%$ of baseline (mean \pm SEM, $N=6$ ) and EPSP slope was $86.09 \pm 10.13 \%$ of baseline (Fig. $1 \mathrm{D}, N=6$ ). In one rat, the population spike decreased below $1.5 \mathrm{mV}(0.57 \mathrm{mV})$, so as above, physiological data were analyzed with and without this case. With the excluded case, population spike amplitude was $106.5 \pm 10.96 \%$ of baseline (Fig. 1C, $N=5$ ) and EPSP slope was $90.97 \pm 10.87 \%$ of baseline $(N=5)$. Following delivery of 30 high-frequency trains, population spike amplitude increased by $88.71 \pm 24.16 \%(N=5$, Fig. $1 \mathrm{C})$ and EPSP slope increased by $32.09 \pm 9.15 \%(N=5)$ compared with $139.5 \pm 27.28 \%(N=6)$ for population spike amplitude and $28.32 \pm$ $3.34 \%(N=6)$ for EPSP slope in control experiments with salinefilled micropipettes. The percent change from baseline for EPSP slope with all cases was $29.08 \pm 8.05 \%$ (Fig. $1 D, N=6$ ).

Immunostaining for p-ser235/236 revealed reduced induction of rpS6 phosphorylation in both the cell bodies and dendritic laminae in the area of LY294002 infusion compared with distant sites (compare Fig. 3A,B with Fig. 3E,F). The block was partial, however, because immunostaining was elevated compared with the contralateral control (Fig. 3G,H). There was a clear band of 
increased immunostaining in the activated dendritic lamina within the area of infusion, but not to the extent seen outside the area of LY294002 infusion.

Quantitative assessments of OD across the dentate gyrus confirmed lower levels of immunostaining within the LY294002 infusion area compared with the distant site in both cell bodies and dendrites (Fig. 3C, $N=6$ ). Analysis of OD in each of the four measuring sites by two-way ANOVA yielded an overall $F_{(6,60)}=3.67, P=$ 0.0036 (Fig. 3D, $N=6$ ). Post hoc analysis with Bonferroni's multiple comparisons tests revealed that immunostaining in distant sections were statistically different than within the infusion area and contralateral sections in the GCL, IML, and MML. Levels of staining in distant sites were significantly different than contralateral sections in the OML. Notably, average OD within the infusion area was also statistically different than the contralateral control in the GCL and MML (Fig. 3D, for statistics, see figure legend; two-way ANOVA, $P<0.05)$. Thus, in contrast to wortmannin, LY294002 attenuated but did not completely block phosphorylation of rpS6 at ser235/236 in the granule cell bodies and dendrites. There was relative sparing of rpS6 phosphorylation in the band of activated synapses, however.

Immunostaining for p-ser240/244 also revealed reduced phosphorylation within the area of LY294002 infusion in comparison with areas distant from the infusion site (compare Fig. 3I,J with Fig. 3M,N). However, quantitative analyses of OD levels in the four measuring sites revealed that differences were not statistically significant for p-ser240/244 $\left[F_{(6,60)}=1.37, P=0.2404\right.$ (Fig. $3 \mathrm{~L}$, $N=6)]$.

\section{MAPK/ERK regulates phosphorylation of rpS6 at activated synapses}

The results using PI3-kinase inhibitors indicate that PI3-kinase is critical for inducing rpS6 phosphorylation throughout the somatodendritic compartment, but another signaling pathway must be acting to locally induce rpS6 phosphorylation at active synapses. One candidate is MAPK/ERK, which is strongly activated by MPP stimulation in an NMDA receptor-dependent manner (Chotiner et al. 2010). To test the involvement of the MAPK signaling pathway, we injected the MEK inhibitor, U0126, into the dentate gyrus. U0126 inhibits activation of ERK1/2 by inhibiting the kinase activity of MEK1/2 (Favata et al. 1998).

In previous studies (O Steward, unpubl.), we found that the approach used above, in which U0126 is allowed to diffuse from a recording micropipette, does not produce consistent inhibition of ERK1/2 phosphorylation. Instead, we used the approach described in Chotiner et al. (2010) in which small volumes $(0.2-0.4 \mu \mathrm{L})$ of U0126 were injected into the dentate gyrus using a Hamilton syringe fitted with a pulled glass micropipette. Recording leads were attached to the metal barrel of the Hamilton microsyringe to record evoked potentials before and after injection. The procedure was to lower the Hamilton/microsyringe into the dentate gyrus and collect test responses for $20 \mathrm{~min}$. Because there was a decrease in response amplitude after placement of the Hamilton/microsyringe, the baseline was calculated as the average response amplitude during the last $10 \mathrm{~min}$ of the preinfusion baseline (see Fig. 1E). Then we injected U0126 $(20 \mu \mathrm{M})$ over a period of $\sim 5 \mathrm{~min}$, waited for $35 \mathrm{~min}$ with no test pulse delivery after making the injection, and then collected test responses for 10 min before initiating HFS.

Following delivery of U0126, the population spike amplitude decreased to $50.49 \pm 6.16 \%$ of preinjection baseline (mean \pm SEM, $N=7)$ and the EPSP slope decreased to $57.83 \pm 10.15 \%(N=7)$. Because of differences in the recording characteristics of the Hamilton micropipette electrode, we did not exclude cases below the $1.5 \mathrm{mV}$ cutoff and instead report the post-LTP data for six cases excluding only one case in which there was a problem with the re- cording. Local delivery of U0126 blocked LTP induction; population spike amplitude increased by $184.93 \pm 55.28 \%$ (Fig. 1E, $N=$ 6) and EPSP slope increased $0.78 \pm 15.78 \%$ (Fig. $1 F, N=6$ ) after HFS. Percent change from baseline for all cases for EPSP slope was $-3.9 \pm 14.13 \%(N=7)$.

A caveat for the physiological recordings for this experiment is that bubbles can develop in the barrel of the Hamilton microsyringe and the fluid volume delivery can cause the tissue to shift so that the electrode is no longer in the optimal location for recording. To confirm that U0126 blocked ERK1/2 phosphorylation, sections were immunostained using an antibody that recognizes phosphorylated ERK1/2 (p-ERK) (Huang et al. 2007). In areas within the U0126 infusion site, p-ERK activation was completely blocked (Fig. 4A,B) in comparison to areas distant from the injection site, where p-ERK immunostaining was increased in the granule cell layer and the dendritic laminae (Fig. 4C,D).

Immunostaining for p-ser235/236 revealed substantial reductions in rpS6 phosphorylation in the dendritic lamina at the injection site in comparison to distant sites (compare Fig. 4E,F to Fig. 4I,J). In contrast, levels of immunostaining in granule cell bodies was comparable to distant sites (for quantification, see Fig. 4G). Notably, there was no band of increased immunostaining in the activated lamina, the MML. Levels of immunostaining in the OML were comparable to the contralateral control (Fig. 4K,L).

Quantitative comparisons of levels of immunostaining within the injection site, distant areas, and the contralateral side in the four measuring sites by two-way ANOVA yielded an overall $F_{(6,72)}=13.02, P<0.0001$ (Fig. $4 \mathrm{H}, N=7$ ). Post hoc analysis with Bonferroni's multiple comparisons tests revealed significant differences between distant sections and contralateral sections at all measuring sites and between sections within the injection site and contralateral sections in the GCL, IML, and MML. Notably, there were also significant differences between distant sections and sections within the injection site in the IML, MML, and OML (Fig. $4 \mathrm{H}$, for statistics, see figure legend; two-way ANOVA, $P<0.05$ ).

Immunostaining for p-ser240/244 within the injection area (Fig. 4Q,R), was comparable to distant sites in the granule cell layer (Fig. 4M,N), whereas levels of immunostaining in the dendritic laminae were reduced (for quantification, see Fig. 4O). Immunostaining in the OML was reduced to control levels while immunostaining in the IML and MML remained elevated compared with controls (Fig. 4S,T).

Quantitative comparisons of levels of immunostaining for p-ser240/244 in the four measuring sites by two-way ANOVA yielded an overall $F_{(6,72)}=3.89, P=0.002$ (Fig. $4 \mathrm{P}, N=7$ ). Post hoc analysis with Bonferroni's multiple comparisons tests revealed a significant difference between distant sections and contralateral sections at all measuring sites and between sections within the injection site and contralateral sections in the GCL, IML, and MML. There was also a significant difference between distant sites versus within the injection site in the MML and OML (Fig. 4P, for statistics, see figure legend; two-way ANOVA, $P<0.05$ ). Thus, in contradistinction to PI3-kinase, the data indicate that MAPK/ERK is primarily responsible for local induction of rpS6 phosphorylation at active synapses.

\section{Local infusion of the mTOR inhibitor, rapamycin, blocks rpS6 phosphorylation throughout the somatodendritic domain, especially phosphorylation at ser240/244}

Our data so far support the idea that MAPK/ERK is primarily responsible for inducing phosphorylation of rpS6 at active synapses, whereas PI3-kinase mediates rpS6 phosphorylation throughout the somatodendritic compartment with a minimal role in the 

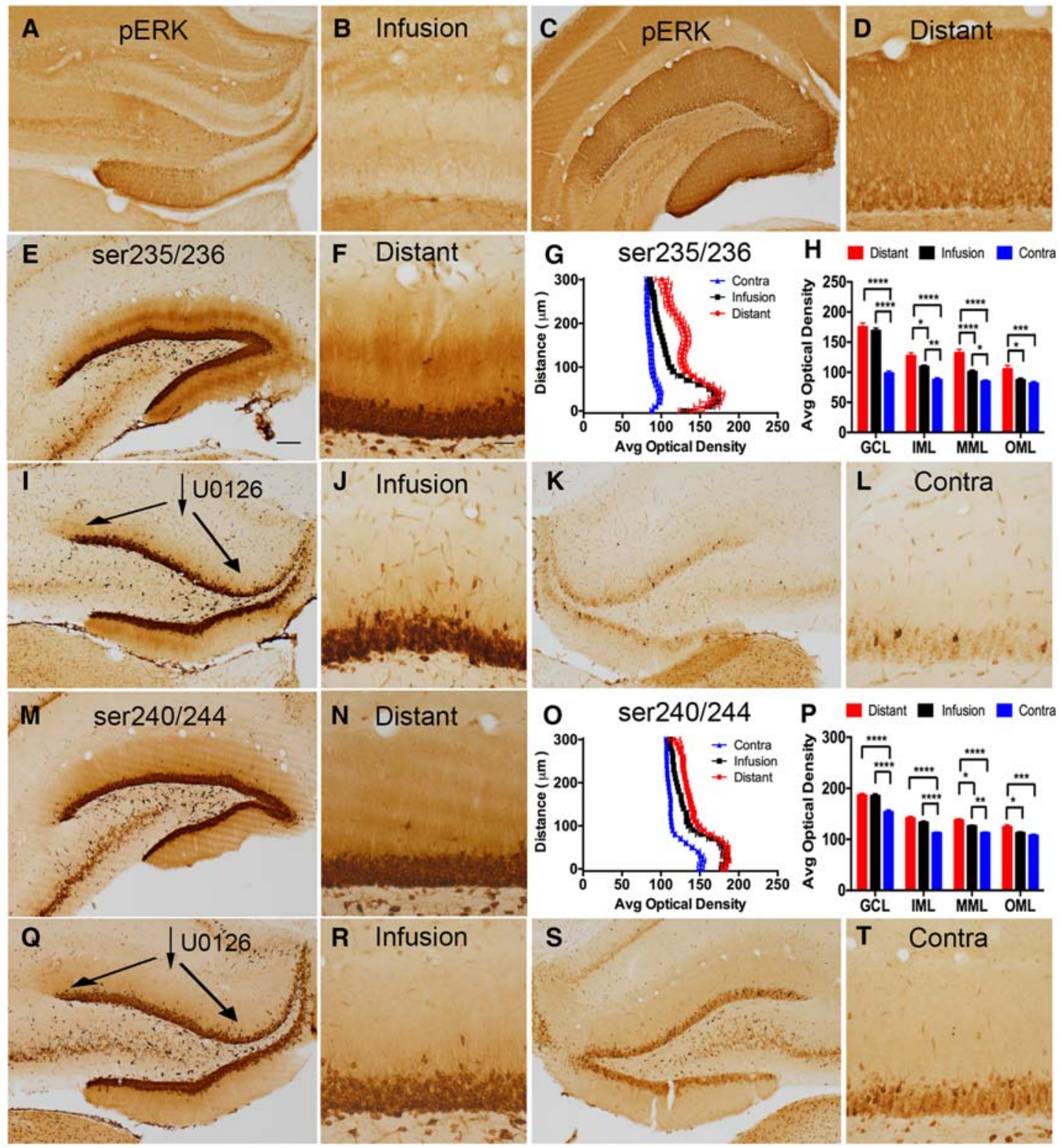

Figure 4. Local infusion of the MEK inhibitor, U0126, attenuates dendritic phosphorylation of rpS6. (A) Immunostaining of phospho-ERK in a section within the injection site. (B) High-magnification image $A$ at the site of infusion. (C) Immunostaining of phospho-ERK in a section distant from the injection site. $(D)$ High-magnification image of $C$. (E) Immunostaining for p-ser235/236 ipsilateral to stimulation in a section distant from the injection site. $(F)$ High-magnification image of $E$. (G) Quantification of average OD across the dorsal blade of the dentate gyrus in ipsilateral sections distant from the injection site, ipsilateral sections within the infusion area, and contralateral, nonstimulated sections. $(H)$ Statistical assessment at four sites along the dentate gyrus, GCL, IML, MML, OML (ser235/236, N =7), error bars represent SEM. Statistical assessment by two-way ANOVA revealed a significant interaction $\left(F_{(6,72)}=13.02, P<0.0001\right)$, a significant main effect of treatment $\left(F_{(2,72)}=121.41, P<0.0001\right)$, and a significant main effect of region $\left(F_{(3,72)}=94.30, P<\right.$ $0.0001)$. Post hoc analysis with Bonferroni's multiple comparisons tests revealed a significant difference between distant sections and contralateral sections at all measuring sites. There was also a significant difference between sections within the infusion area and contralateral sections in the GCL, IML, and MML. Notably, there was a significant difference between distant sections and sections within the infusion area in the IML, MML, and OML (two-way ANOVA, $P<$ 0.05). (I) Immunostaining of p-ser235/236 ipsilateral to the stimulation in a section within the injection site in the presence of U0126. (J) High-magnification image of $I$. Note local infusion of U0126 reduces phosphorylation of rpS6 throughout the molecular layer of the dentate gyrus. The distinct band of rpS6 phosphorylation is not discernable. $(K)$ Immunostaining of p-ser235/236 contralateral to the stimulation. (L) High-magnification image of $K$. (M) Immunostaining of p-ser240/244 in a section distant from the injection site. ( $N$ ) High-magnification image of $M$. $(O)$ Quantification of average OD across the dorsal blade of the dentate gyrus in ipsilateral sections distant from the injection site, ipsilateral sections within the injection site, and contralateral sections. $(P)$ Statistical assessment at four sites along the dentate gyrus, GCL, IML, MML, OML (ser240/244, $N=7)$, error bars represent SEM. Statistical assessment by two-way ANOVA revealed a significant interaction $\left(F_{(6,72)}=3.89, P=0.0020\right)$, a significant main effect of treatment $\left(F_{(2,72)}=83.75, P<0.0001\right)$, and a significant main effect of region $\left(F_{(3,72)}=254.91, P<0.0001\right)$. Post hoc analysis with Bonferroni's multiple comparisons tests revealed a significant difference between distant sections and contralateral sections at all measuring sites. There was also a significant difference between sections within the infusion area and contralateral sections in the GCL, IML, and MML. Notably, there was also a significant difference between distant sections and sections within the infusion area in the MML and OML (two-way ANOVA, $P<0.05)$. (Q) Immunostaining of p-ser240/244 ipsilateral to stimulation in a section within the U0126 injection site. (R) High-magnification image of $Q$. Note the reduction of rpS6 phosphorylation in the dendritic laminae. (S) Immunostaining of p-ser240/244 contralateral to the stimulation. ( $T$ ) High-magnification image of S. Scale bars: $E, 200 \mu \mathrm{m} ; F, 50 \mu \mathrm{m}$. 
region of activated synapses. We next explored whether the story holds for the downstream mediators of PI3-kinase and MAPK/ ERK. We began by assessing the role of mTOR by locally infusing rapamycin. For this, we returned to the strategy of delivering pharmacological agents via diffusion from a recording micropipette electrode. If MAPK/ERK is primarily responsible for inducing phosphorylation of rpS6 at active synapses and PI3-kinase, acting through mTOR/S6K1, is primarily responsible for inducing rpS6 phosphorylation throughout the somatodendritic compartments with a minimal role in the activated region, one prediction is that rapamycin will block phosphorylation throughout the somatodendritic compartments (GCL, IML, OML) and spare phosphorylation in the activated dendritic lamina (MML). In addition, because phosphorylation at ser240/244 is thought to be mediated primarily by PI3-kinase/mTOR (Roux et al. 2007), a second prediction is that phosphorylation at ser240/244 will be more affected than phosphorylation at ser235/236.

Following replacement of the saline-filled micropipette with the rapamycin-filled micropipette, population spike amplitude was $78.17 \pm 18.58 \%$ of baseline (mean \pm SEM, $N=5$ ) and EPSP slope was $139.4 \pm 51.89 \%$ of baseline $(N=5)$. In two cases, the population spike decreased below $1.5 \mathrm{mV}(0.52-1.40 \mathrm{mV})$, so physiological data were analyzed with and without these values. Population spike amplitude after electrode exchange with the excluded cases was $106.4 \pm 11.89 \%$ of baseline (Fig. $1 \mathrm{G}, N=3$ ) and EPSP slope was $87.26 \pm 12.38 \%$ of baseline (Fig. $1 \mathrm{H}, N=3$ ). Following delivery of HFS, population spike amplitude increased by $167.8 \pm 18.16 \%$ (Fig. $1 \mathrm{G}, N=3$ ) and EPSP slope increased by $50.53 \pm 11.61 \%$ (Fig. $1 \mathrm{H}, N=3)$ compared with $139.5 \pm 27.28 \%(N=6)$ for population spike amplitude and $28.32 \pm 3.34 \%(N=6)$ for EPSP slope in control experiments. The percent change from baseline for EPSP slope with all cases was $96.65 \pm 42.36 \%(N=5)$.

Because induction of rpS6 phosphorylation at ser240/244 is mediated primarily by mTOR activation, a positive control for the effectiveness of rapamycin is the blockade of increases in immunostaining for p-ser240/244. Accordingly, the findings for p-ser240/244 are summarized first although the order of presentation in the figure is as in Figure 2 to facilitate comparison.

Immunostaining for $\mathrm{p}$-ser240/244 revealed strong attenuation of rpS6 phosphorylation in granule cell bodies and dendrites within the infusion area in comparison to distant sites (cf. Fig. 5I,J and Fig. 5M,N; for quantification, see Fig. 5K). Immunostaining in the granule cell layer and dendritic lamina within the infusion site were reduced to levels comparable to the contralateral control (Fig. 5O,P), indicating complete blockade.

Quantitative comparisons of levels of immunostaining for p-ser240/244 in the four measuring sites by two-way ANOVA yielded an overall $F_{(6,48)}=3.05, P=0.0131$ (Fig. $5 \mathrm{~L}, N=5$ ). Post hoc analysis with Bonferroni's multiple comparisons tests revealed that distant sections were statistically different than sections within the infusion area and contralateral sections in all regions. Notably, for p-ser240/244, immunostaining within the infusion area was significantly different than contralateral sites in the GCL and IML (Fig. 5L, for statistics, see figure legend; two-way ANOVA, $P<0.05)$.

Phosphorylation of rpS6 at ser235/236 can be mediated by different signaling pathways, so assessing the effects of rapamycin provides insight into the contribution of mTOR-mediated increases in rpS6 phosphorylation. Immunostaining for p-ser235/236 confirmed robust activation of rpS6 phosphorylation in areas distant from the rapamycin-filled micropipette (Fig. 5A,B). Within the infusion area (Fig. 5E,F), phosphorylation of rpS6 was blocked in the granule cell bodies, whereas the band of increased immunostaining in the MML was partially preserved in some animals (three out of five cases, one of which is illustrated in Fig. 5E,F). Despite the partial sparing of dendritic labeling in the case shown in Figure 5E and $\mathrm{F}$, the quantitative analysis of $\mathrm{OD}$ across the molecular layer for all cases revealed reductions in immunostaining to the levels of the contralateral control in both cell body and dendritic lamina (for quantification, see Fig. 5C). Comparisons of levels of immunostaining for p-ser235/236 in the four measuring sites by two-way ANOVA yielded an overall $F_{(6,48)}=7.29, P<0.0001$ (Fig. $5 \mathrm{D}, N=$ $5)$. Post hoc analysis with Bonferroni's multiple comparisons tests revealed that distant sections were statistically different that sections within the infusion area and contralateral sections in all regions (Fig. 5D, for statistics, see figure legend; two-way ANOVA, $P<0.05)$.

Taken at face value, the quantitative results indicate that mTOR activation is critical for induction of rpS6 phosphorylation in both the granule cell bodies and dendrites for both p-ser235/236 and p-ser240/244. However, preservation of the band of increased labeling in the MML in some cases (such as the one shown in Fig. $5 \mathrm{E}, \mathrm{F})$ points to the interpretation that $\mathrm{mTOR}$ is more critical for rpS6 phosphorylation throughout the somatodendritic compartment and additional pathways also contribute to induction of rpS6 phosphorylation at active synapses.

\section{Local infusion of the RSK inhibitor, SLO1O1-1, partially attenuates rpS6 phosphorylation at activated synapses and in granule cell bodies}

One kinase that mediates phosphorylation of rpS6 is p90 ribosomal protein S6 kinase (RSK) (Roux et al. 2007). It is thought that RSK can be activated by both 3-phosphoinositide-dependent protein kinase-1 (PDK1) (Jensen et al. 1999; Frödin et al. 2000) and the MAPK/ERK signaling pathway (for review, see Anjum and Blenis 2008). If induction of rpS6 phosphorylation at active synapses is mediated primarily by MAPK/ERK acting through RSK, then inhibition of RSK should block the development of the band of increased staining at active synapses and the portion of the phosphorylation in cell bodies that is mediated by MAPK/ERK. Also, inhibition of RSK should have no effect on phosphorylation of rpS6 at ser240/244, as this subset of serine sites are primarily mTOR-dependent. We assessed this by infusing the selective RSK inhibitor, SL0101-1, into the dentate gyrus.

Following replacement of a saline-filled micropipette, with an SL0101-1-filled micropipette, population spike amplitude was $83.77 \pm 9.46 \%$ of baseline (mean \pm SEM, Fig. $1 \mathrm{I}, N=7$ ) and EPSP slope was $83.86 \pm 7.60 \%$ of baseline (Fig. $1 \mathrm{~J}, N=7$ ). Following delivery of 30 HFS trains, the population spike amplitude increased by $188.1 \pm 36.45 \%$ (Fig. 1 I, $N=7$ ) and EPSP slope increased by $50.23 \pm 5.12 \%$ (Fig. $1 \mathrm{~J}, N=7$ ) compared with $139.5 \pm 27.28 \%$ $(N=6)$ for population spike amplitude and $28.32 \pm 3.34 \%(N=6)$ for EPSP slope in control experiments with saline-filled micropipettes.

Immunostaining for p-ser235/236 revealed substantial reductions of rpS6 phosphorylation in both the granule cell layer and dendritic layers within the area of SL0101-1 infusion in comparison to distant sites (compare Fig. 6A,B to Fig. 6E,F). Nevertheless, the band of increased immunostaining for rpS6 phosphorylation at activated synapses remained apparent in the MML. Overall, the attenuation of rpS6 phosphorylation was partial, however, as immunostaining within the infusion area was higher than immunostaining levels on the contralateral side (Fig. 6G,H).

Quantitative analysis confirmed a reduction in immunostaining in both the dendritic lamina and granule cell bodies (Fig. 6C). Quantitative comparisons of levels of immunostaining for p-ser235/236 in the four measuring sites by two-way ANOVA yielded an overall $F_{(6,72)}=5.52, P<0.0001$ for p-ser235/236 (Fig. 6D, $N=$ $7)$. Post hoc analysis with Bonferroni's multiple comparisons tests revealed a significant difference between distant sections and 

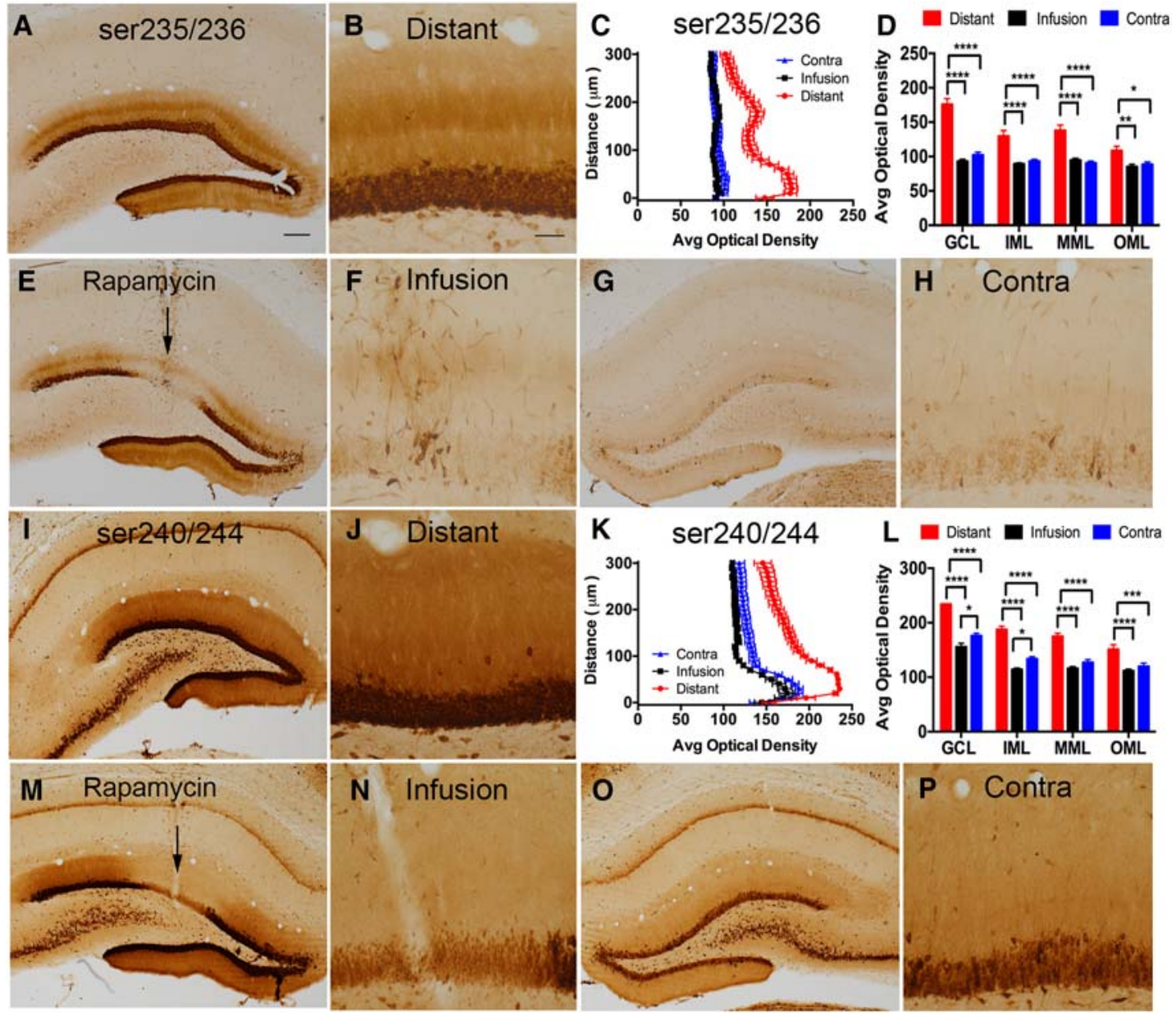

Figure 5. Local infusion of mTOR inhibitor, rapamycin, strongly inhibits phosphorylation of rpS6. (A) Immunostaining for $p$-ser $235 / 236 \mathrm{ipsilateral} \mathrm{to} \mathrm{stim-}$ ulation in a section distant from the infusion area. (B) High-magnification image of $A$. (C) Quantification of average OD across the dorsal blade of the dentate gyrus in ipsilateral sections distant from the infusion area, ipsilateral sections within the infusion area, and contralateral, nonstimulated sections. (D) Statistical assessment at four sites along the dentate gyrus, GCL, IML, MML, OML (ser235/236, N=5), error bars represent SEM. Statistical assessment by two-way ANOVA revealed a significant interaction $\left(F_{(6,48)}=7.29, P<0.0001\right)$, a significant main effect of treatment $\left(F_{(2.48)}=105.62, P<0.0001\right)$, and a significant main effect of region $\left(F_{(3,48)}=17.00, P<0.0001\right)$. Post hoc analysis with Bonferroni's multiple comparisons tests revealed that distant sections were statistically different than sections within the infusion area and contralateral sections in all regions (two-way ANOVA, $P<0.05)$. $(E)$ Immunostaining of p-ser235/236 ipsilateral to the stimulation in a section within the rapamycin infusion area. $(F)$ High-magnification image of $E$. Note rapamycin infusion completely blocks phosphorylation of rpS6 in the GCL and throughout the molecular layer of the dentate gyrus. The distinct band of rpS6 phosphorylation remained in some instances in sections within the infusion area. $(G)$ Immunostaining of p-ser235/236 contralateral to the stimulation. $(H)$ High-magnification image of $G$. (I) Immunostaining of p-ser240/244 in a section distant from the infusion area. ( $/)$ High-magnification image of $I .(K)$ Quantification of average OD across the dorsal blade of the dentate gyrus in ipsilateral sections distant from the infusion area, ipsilateral sections within the infusion area, and contralateral sections. (L) Statistical assessment at four sites along the dentate gyrus, GCL, IML, MML, OML (ser240/244, $N=5$ ), error bars represent SEM. Statistical assessment by two-way ANOVA revealed a significant interaction $\left(F_{(6,48)}=3.05, P=0.0131\right)$, a significant main effect of treatment $\left(F_{(2,48)}=162.19, P<0.0001\right)$, and a significant main effect of region $\left(F_{(3,48)}=80.86, P<0.0001\right)$. Post hoc analysis with Bonferroni's multiple comparisons tests revealed that distant sections were statistically different than sections within the infusion area and contralateral sections in all regions. Notably, sections within the infusion area were statistically different than contralateral sections in the GCL and IML (two-way ANOVA, $P<0.05)$. (M) Immunostaining of $p$-ser240/244 ipsilateral to stimulation in a section within the rapamycin infusion area. $(N)$ High-magnification image of $M$. $(O)$ Immunostaining of p-ser240/244 contralateral to the stimulation. $(P)$ High-magnification image of $O$. Scale bars: $A, 200 \mu \mathrm{m} ; B, 50 \mu \mathrm{m}$.

contralateral sections in all regions. There was also a significant difference between distant sections and sections within the infusion area in the GCL, IML, and MML. Notably, there was a significant difference between sections within the infusion area and contralateral sections in all regions (Fig. 6D, for statistics, see figure legend; two-way ANOVA, $P<0.05$ ).

Immunostaining for p-ser240/244 revealed slightly lower levels of rpS6 phosphorylation in the dendritic laminae within the infusion area in comparison to distant sites (cf. Fig. 6I,J and Fig. 6M, $\mathrm{N}$ ), whereas levels of immunostaining for rpS6 phosphorylation in granule cell bodies were comparable to distant sites (compare
Fig. $6 \mathrm{~J}, \mathrm{~N})$ and elevated compared with the contralateral control (Fig. 6O,P).

Quantitative analysis revealed no reduction in immunostaining throughout the postsynaptic cell (Fig. 6K). Quantitative comparisons of levels of immunostaining for p-ser240/244 in the four measuring sites by two-way ANOVA yielded an overall $F_{(6,72)}=5.07, P=0.0002$ (Fig. $6 \mathrm{~L}, N=7$ ). Post hoc analysis with Bonferroni's multiple comparisons tests revealed that distant sections and sections within the infusion area were statistically different than contralateral sections in all regions (Fig. 6L, for statistics, see figure legend; two-way ANOVA, $P<0.05$ ). 


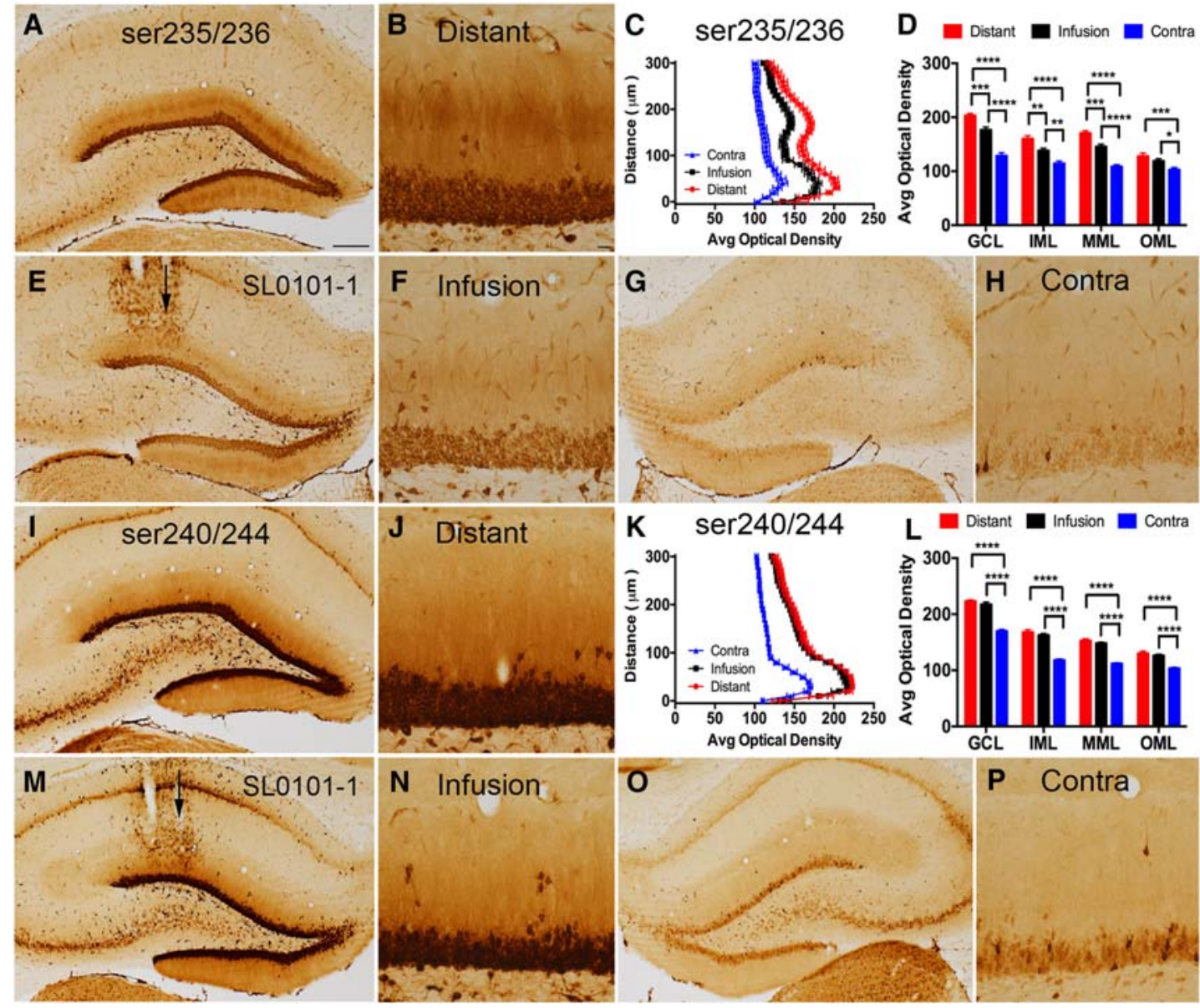

Figure 6. Local infusion of RSK inhibitor, SL0101-1, partially attenuates phosphorylation of rpS6. (A) Immunostaining for p-ser $235 / 236$ ipsilateral to stimulation in a section distant from the infusion area. (B) High-magnification image of $A$. (C) Quantification of average OD across the dorsal blade of the dentate gyrus in ipsilateral sections distant from the infusion area, ipsilateral sections within the infusion area, and contralateral, nonstimulated sections. (D) Statistical assessment at four sites along the dentate gyrus, GCL, IML, MML, OML (ser235/236, N=7), error bars represent SEM. Statistical assessment by two-way ANOVA revealed a significant interaction $\left(F_{(6,72)}=5.52, P<0.0001\right)$, a significant main effect of treatment $\left(F_{(2,72)}=124.82, P<0.0001\right)$, and a significant main effect of region $\left(F_{(3,72)}=64.93, P<0.0001\right)$. Post hoc analysis with Bonferroni's multiple comparisons tests revealed a significant difference between distant sections and contralateral sections in all regions. There was also a significant difference between distant sections and sections within the infusion area in the GCL, IML, and MML. Notably, there was a significant difference between sections within the infusion area and contralateral sections in all regions (two-way ANOVA, $P<0.05$ ). (E) Immunostaining of p-ser235/236 ipsilateral to the stimulation in a section within the infusion area in the presence of SL0101-1 (arrow denotes SL0101-1 electrode track). ( $F$ ) High-magnification image of $E$. Note local infusion of SL0101-1 attenuates phosphorylation of rpS6 in the GCL and throughout the molecular layer of the dentate gyrus. The distinct band of rpS6 phosphorylation remained elevated above control levels. $(G)$ Immunostaining of p-ser235/236 contralateral to the stimulation. $(H)$ High-magnification image of $G$. (I) Immunostaining of p-ser240/244 in a section distant from the infusion area. ( $)$ High-magnification image of $I$. ( $K$ ) Quantification of average OD across the dorsal blade of the dentate gyrus in ipsilateral sections distant from the infusion area, ipsilateral sections within the infusion area, and contralateral sections. ( $L$ ) Statistical assessment at four sites along the dentate gyrus, GCL, IML, MML, OML (ser240/244, N=7), error bars represent SEM. Statistical assessment by two-way ANOVA revealed a significant interaction $\left(F_{(6,72)}=5.07, P=0.0002\right)$, a significant main effect of treatment $\left(F_{(2,72)}=248.25, P<0.0001\right)$, and a significant main effect of region $\left(F_{(3,72)}=444.19, P<0.0001\right)$. Post hoc analysis with Bonferroni's multiple comparisons tests revealed that distant sections and sections within the infusion area were statistically different than contralateral sections in all regions (two-way ANOVA, $P<0.05$ ). $(M)$ Immunostaining of $p$-ser240/244 ipsilateral to stimulation in a section within the SL0101-1 infusion area. ( $N$ ) High-magnification image of $M$. (O) Immunostaining of $\mathrm{p}$-ser240/244 contralateral to the stimulation. (P) High-magnification image of $O$. Scale bars: $A, 200 \mu \mathrm{m} ; B, 20 \mu \mathrm{m}$.

Together these data indicate that RSK primarily contributes to rpS6 phosphorylation at ser235/236 throughout the somatodendritic compartment and plays a minimal role, if any, in phosphorylation of rpS6 at ser240/244.

\section{Local infusion of the S6K1 inhibitor, PF4708671, partially} attenuates rpS6 phosphorylation in granule cell bodies and dendritic laminae

Two mTOR-dependent kinases that mediate phosphorylation of rpS6 are S6K1 and S6K2 (Dufner and Thomas 1999). S6K1 has been shown to localize in the nucleus and cytosol, while S6K2 is highly restricted to the nucleus (Lee-Fruman et al. 1999; Park et al. 2002). Activation of S6K1 is reported to be primarily by mTOR (Thoreen et al. 2012), whereas S6K2 may also be regulated by the downstream substrate of ERK, RSK (Wang et al. 2001a). If PI3-kinase acting through mTOR/S6K1 is primarily responsible for inducing phosphorylation of rpS6 throughout the somatodendritic compartment with a minimal role at activated synapses, the prediction is that blockade of S6K1 will block phosphorylation in cell bodies and spare activation in dendrites. To test this, we infused the selective S6K1 inhibitor, PF4708671, into the dentate gyrus. 
PF4708671 inhibits S6K1 by preventing its phosphorylation activity and does not target S6K2 (Pearce et al. 2010). Again, because phosphorylation at ser240/244 is mediated primarily by mTOR, we reasoned that a positive control for the effectiveness of PF4708671 would be a reduction in immunostaining for $p$ ser240/244, so the findings for p-ser240/244 are summarized first.

Following replacement of the saline-filled micropipette with the PF4708671-filled micropipette, response amplitude was $93.84 \pm 45.03 \%$ of baseline (mean \pm SEM, $N=7$ ) for the population spike amplitude and $88.13 \pm 39.23 \%$ of baseline $(N=7)$ for EPSP slope. In four cases, the population spike was below $1.5 \mathrm{mV}$ $(0.16-1.3 \mathrm{mV})$, so as above, data are reported with and without these cases. The baseline after micropipette exchange with the excluded cases was $83.53 \pm 20.56 \%$ of baseline (Fig. $1 \mathrm{~K}, N=3$ ) for population spike amplitude and $81.64 \pm 5.47 \%$ of baseline (Fig. $1 \mathrm{~L}, N=$ 3 ) for EPSP slope. Following the delivery of 30 trains of HFS, population spike amplitude increased by $155 \pm 29.85 \%$ (Fig. $1 \mathrm{~K}, N=3$ ) and EPSP slope increased by $24.72 \pm 1.4 \%$ (Fig. $1 \mathrm{~L}, N=3$ ) compared with $139.5 \pm 27.28 \%(N=6)$ for population spike amplitude and $28.32 \pm 3.34 \%(N=6)$ for EPSP slope in control experiments with saline-filled micropipettes. The percent change from baseline for EPSP slope with all cases was $17.66 \pm 8.48 \%(N=7)$.

Immunostaining for p-ser240/244 revealed substantial reductions in rpS6 phosphorylation in granule cell bodies and dendritic laminae within the infusion area in comparison to distant sites (cf. Fig. 7I,J and Fig. 7M,N; for quantification, see Fig. 7K). Indeed, only a few scattered granule cells were heavily stained whereas most granule cells exhibited low-moderate levels of immunostaining (compare Fig. 7J-N). The attenuation was partial, however, because immunostaining was higher than on the contralateral side (Fig. 7O,P).

Quantitative comparisons of levels of immunostaining for p-ser240/244 in the four measuring sites by two-way ANOVA yielded an overall $F_{(6,72)}=5.29, P=0.0001$ (Fig. 7L, $N=7$ ). Post hoc analysis with Bonferroni's multiple comparisons tests revealed that distant sections were statistically different than sections within the infusion area and contralateral sections in all regions. Notably, sections within the infusion area were also statistically different than contralateral sections in the GCL, IML, and MML (Fig. 7L, for statistics, see figure legend; two-way ANOVA, $P<$ $0.05)$. Taken together, these results indicate only partial blockade of rpS6 phosphorylation at ser240/244 in both cell bodies and dendrites.

Immunostaining for p-ser235/236 revealed reductions in rpS6 phosphorylation in both granule cells bodies and dendritic laminae within the infusion area in comparison to distant sites (cf. Fig. 7A,B and Fig. 7E,F; for quantification, see Fig. 7C). A band of increased immunostaining was still evident in the region of activated synapses (Fig. 7F), but levels of immunostaining in the band were not as elevated as in areas outside the infusion site (Fig. 7B).

Quantitative comparisons of levels of immunostaining for p-ser235/236 in the four measuring sites by two-way ANOVA yielded an overall $F_{(6,72)}=7.50, P<0.0001$ (Fig. 7D, $N=7$ ). Post hoc analysis with Bonferroni's multiple comparisons tests revealed that distant sections were statistically different than contralateral sections in all regions and sections within the infusion area were significantly different than contralateral sections in the GCL, IML, and MML. Notably, distant sections were also statistically different than sections within the infusion area in the IML and MML (Fig. 7D, for statistics, see figure legend; two-way ANOVA, $P<0.05)$.

The results collectively reveal a different pattern than predicted in that PF4708671 produced partial blockade of rpS6 phosphorylation for p-ser240/244 in cell bodies and dendrites and partial blockade of rpS6 phosphorylation for p-ser235/236 predominately in the dendritic lamina. It may be that under the experimental conditions here, PF4708671 is not acting with the expected specificity or that inhibition of S6K1 is compensated by other kinases resulting in a partial inhibition. These caveats will be considered further in the Discussion.

\section{Local infusion of pharmacological inhibitors does not affect levels of total rpS6}

Previously, we reported that HFS-induced phosphorylation of rpS6 is not associated with increases in total rpS6 (Pirbhoy et al. 2016). Similarly, immunostaining of sections from cases reported above that had received different pharmacological agents revealed no changes in total rpS6 due either to stimulation alone or following delivery of any of the inhibitors. Supplemental Figure S1 shows nearby infusion site sections of the images represented in the figures above for each pharmacological agent immunostained for total rpS6. Thus, changes in immunostaining observed with phospho-specific antibodies described above indicate changes in phosphorylation, not changes in rpS6 protein levels.

\section{Induction of rpS6 phosphorylation depends on signals from NMDA receptor activation, not strong depolarization or cell firing}

Induction of rpS6 phosphorylation with HFS requires NMDA receptor activation, but subsequent signals remain to be defined. For example, HFS induces strong postsynaptic depolarization and massive cell discharge, both of which would activate voltagegated calcium channels. To identify which postsynaptic events were responsible for inducing rpS6 phosphorylation, we took advantage of the fact that local delivery of the GABA receptor antagonist, bicuculline, leads to strong depolarization and multiple population spikes in response to single pulse stimulation of the perforant path that does not induce LTP (Steward et al. 1990).

For this experiment, baseline responses were collected with a saline-filled microelectrode, then the saline microelectrode was replaced with a microelectrode filled with $8 \mathrm{mM}$ bicuculline, and test pulse stimulation was delivered at $1 / 10 \mathrm{sec}$ for $1 \mathrm{~h}$.

Figure 8A illustrates typical control responses recorded via the saline-filled micropipette with single pulse stimulation of the perforant path. Immediately after placement of the bicuculline micropipette, the disinhibitory effects of the bicuculline were apparent; in contrast to the single population spike-evoked with single test pulses (Fig. 8A), there were multiple population spikes in response to each pulse and the amplitude with a characteristic inter-spike interval (Fig. 8B).

Immunostaining for p-ser235/236 after $1 \mathrm{~h}$ of single pulse stimulation with bicuculline revealed strong activation of rpS6 phosphorylation in an area $\sim 1 \mathrm{~mm}$ in diameter around the micropipette (Fig. 8E,F) with a band of increased immunostaining in the activated dendritic lamina (MML). Levels of immunostaining in sites distant from the bicuculline infusion were comparable to the unstimulated side (Fig. 8G,H). There were also increases in immunostaining for p-ser240/244 in the granule cell bodies and proximal dendrites in the area surrounding the bicuculline-filled micropipette (Fig. 8I,J).

The strong discharge of granule cells due to bicuculline infusion would activate hilar neurons that mediate recurrent excitatory feedback to granule cells, which likely activates NMDA receptors. Thus, the increases in immunostaining observed with phosphospecific antibodies could be due to NMDA receptor activation rather than depolarization and cell discharge. To test this, we carried out another experiment in which we combined the NMDA receptor antagonist, APV, with bicuculline in the micropipette recording 

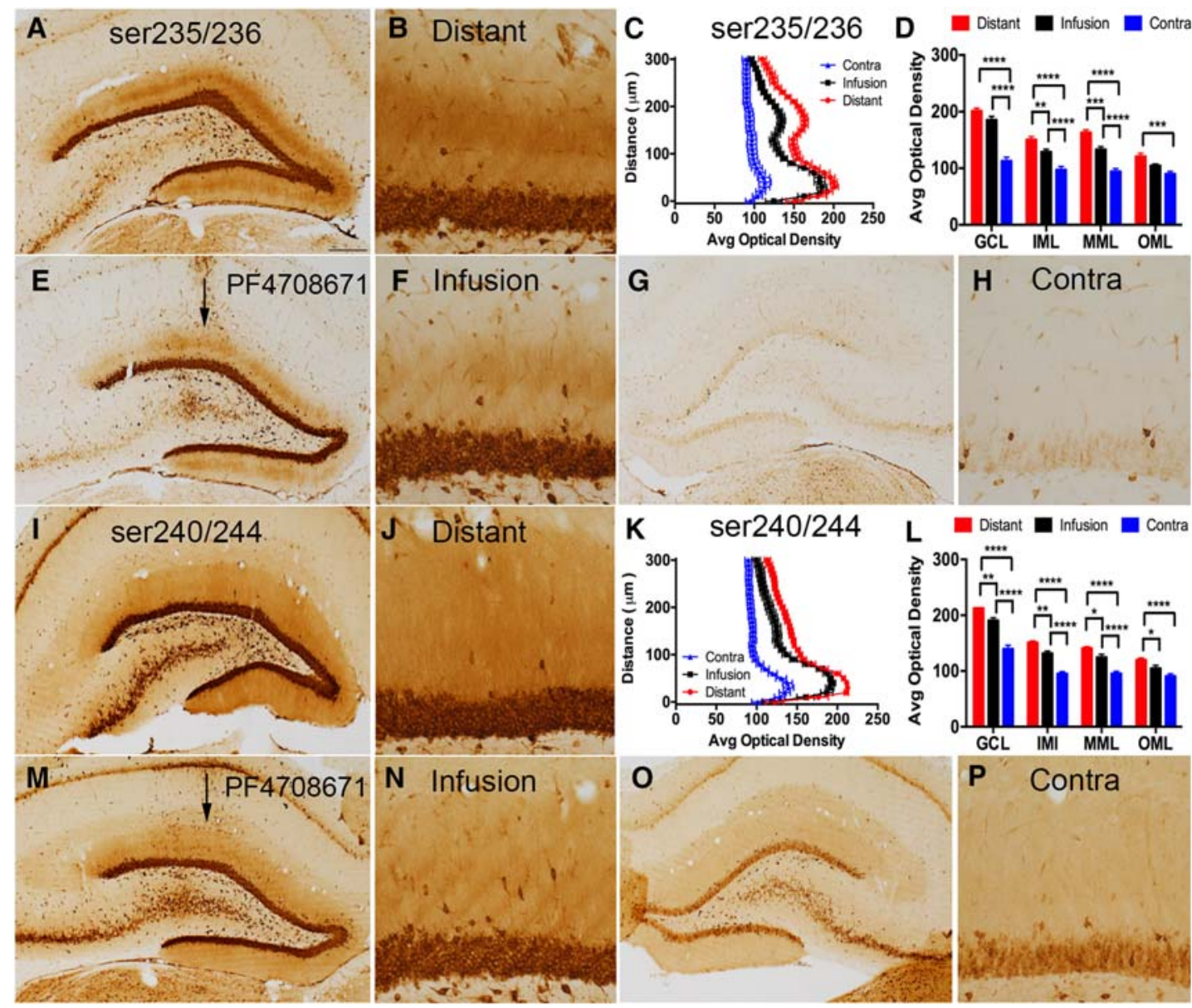

Figure 7. Local infusion of the S6K1 inhibitor, PF4708671, partially attenuates phosphorylation of rpS6. (A) Immunostaining for p-ser235/236 ipsilateral to stimulation in a section distant from the infusion area. (B) High-magnification image of $A$. (C) Quantification of average OD across the dorsal blade of the dentate gyrus in ipsilateral sections distant from the infusion area, ipsilateral sections within the infusion area, and contralateral, nonstimulated sections. (D) Statistical assessment at four sites along the dentate gyrus, GCL, IML, MML, OML (ser235/236, $N=7$ ), error bars represent SEM. Statistical assessment by two-way ANOVA revealed a significant interaction $\left(F_{(6,72)}=7.50, P<0.0001\right)$, a significant main effect of treatment $\left(F_{(2,72)}=139.31, P<0.0001\right)$, and a significant main effect of region $\left(F_{(3,72)}=72.31, P<0.0001\right)$. Post hoc analysis with Bonferroni's multiple comparisons tests revealed that distant sections were statistically different than contralateral sections in all regions and sections within the infusion area were significantly different than contralateral sections in the GCL, IML, and MML. Notably, distant sections were also statistically different than sections within the infusion area in the IML and MML (two-way ANOVA, $P<0.05$ ). (E) Immunostaining of $p$-ser235/236 ipsilateral to the stimulation in a section within the infusion area in the presence of PF4708671 (arrow denotes electrode track). (F) High-magnification image of $E$. Note local infusion of PF4708671 attenuates phosphorylation of rpS6 throughout the molecular layer of the dentate gyrus. The distinct band of rpS6 phosphorylation remained discernable. $(G)$ Immunostaining of p-ser235/236 contralateral to the stimulation. (H) High-magnification image of G. (I) Immunostaining of p-ser240/244 in a section distant from the infusion area. (J) High-magnification image of $I$. (K) Quantification of average OD across the dorsal blade of the dentate gyrus in ipsilateral sections distant from the infusion area, ipsilateral sections within the infusion area, and contralateral sections. $(L)$ Statistical assessment at four sites along the dentate gyrus, GCL, IML, MML, OML (ser240/244, $N=7)$, error bars represent SEM. Statistical assessment by two-way ANOVA revealed a significant interaction $\left(F_{(6,72)}=\right.$ 5.29, $P=0.0001)$, a significant main effect of treatment $\left(F_{(2,72)}=147.93, P<0.0001\right)$, and a significant main effect of region $\left(F_{(3,72)}=180.77, P<0.0001\right)$. Post hoc analysis with Bonferroni's multiple comparisons tests revealed that distant sections were statistically different than sections within the infusion area and contralateral sections in all regions. Notably, sections within the infusion area were also statistically different than contralateral sections in the GCL, IML, and MML (two-way ANOVA, $P<0.05$ ). (M) Immunostaining of $p$-ser240/244 ipsilateral to stimulation in a section within the infusion area in the presence of PF4708671 (arrow denotes electrode track). ( $N$ ) High-magnification image of $M$. (O) Immunostaining of p-ser240/244 contralateral to the stimulation. $(P)$ High-magnification image of $O$. Scale bars: $A, 200 \mu \mathrm{m} ; B, 20 \mu \mathrm{m}$.

electrode (APV: $51 \mathrm{mM}$; bicuculline: $8 \mathrm{mM}$ ). As above, single population spikes were recorded via the saline micropipette (Fig. 8C) whereas multiple population spikes were evident after placement of the bicuculline/APV micropipette (Fig. 8D).

After single pulse stimulation delivered at $1 / 10 \mathrm{sec}$ for $1 \mathrm{~h}$, immunostaining for either p-ser235/236 (Fig. 8M,N) or p-ser240/ 244 (Fig. 8Q,R) revealed complete blockade of rpS6 phosphorylation when compared with cases with bicuculline alone (Fig. 8E,F; Fig. 8I,J). Collectively, these results indicate that phosphorylation of rpS6 is not mediated by depolarization or strong cell discharge and instead depends on signals generated directly via NMDA receptor activation.

\section{Discussion}

Previously (Pirbhoy et al. 2016), we showed that HFS of the MPP induced phosphorylation of rpS6 at ser235/236 in cell bodies and dendrites of dentate granule cells with a selectively higher level of labeling in the zone of activated synapses. In contrast, phosphorylation at ser240/244 occurred at cell bodies and throughout 


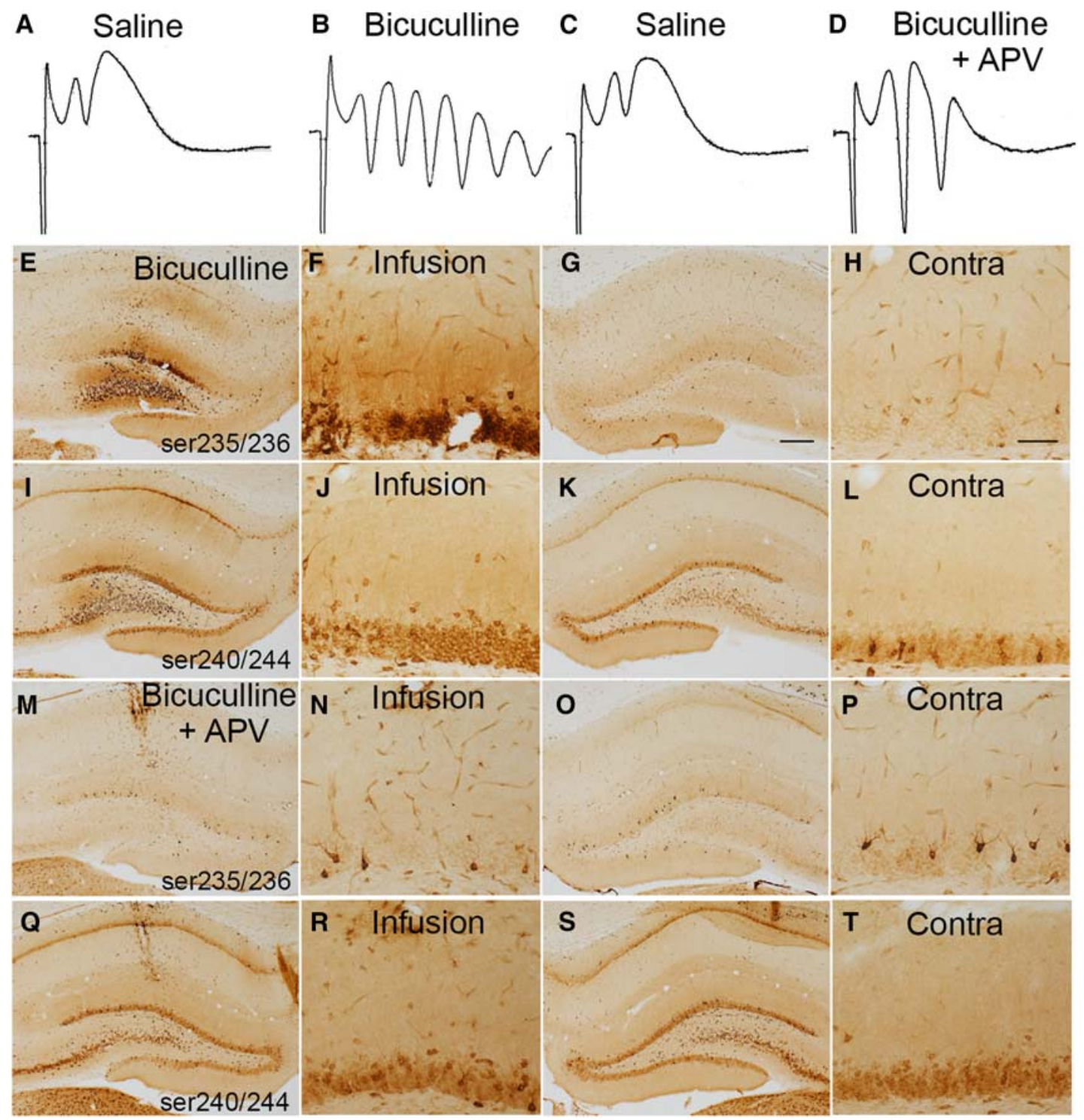

Figure 8. Induction of rpS6 phosphorylation depends on NMDA receptor activation. (A) Evoked responses recorded with a saline-filled microelectrode. (B) Evoked responses recorded with a bicuculline-filled microelectrode. (C) Evoked responses recorded with saline-microelectrode. (D) Evoked responses recorded with microelectrode filled with bicuculline and APV combined. (E) Immunostaining for p-ser235/236 in a section ipsilateral to test pulse stimulation in the presence of bicuculline. $(F)$ High-magnification image of $E$. (G) Immunostaining for p-ser235/236 in a section contralateral to test pulse stimulation. (H) High-magnification image of $G$. (I) Immunostaining for p-ser240/244 in a section ipsilateral to test pulse stimulation in the presence of bicuculline. (J) High-magnification image of $I$. $(K)$ Immunostaining for $p$-ser240/244 in a section contralateral to test pulse stimulation. (L) High-magnification image of $K .(M)$ Immunostaining for p-ser235/236 in a section ipsilateral to test pulse stimulation in the presence of bicuculline and APV combined. (N) High-magnification image of $M$. (O) Immunostaining for p-ser235/236 in a section contralateral to the test pulse stimulation. $(P)$ High-magnification of $O$. (Q) Immunostaining for $p$-ser240/244 in a section ipsilateral to test pulse stimulation in the presence of bicuculline and APV combined. (R) High-magnification image of Q. $(S)$ Immunostaining for p-ser240/244 in a section contralateral to the test pulse stimulation. $(T)$ High-magnification image of S. Scale bars: $G, 200 \mu \mathrm{m} ; \mathrm{H}, 50 \mu \mathrm{m}$.

the dendritic lamina without a band of increased labeling in the zone of activated synapses (see also Panja et al. 2009). We term this generalized somatodendritic activation. Here, we show that: (1) local blockade of MAPK/ERK attenuated p-ser235/236 in the activated dendritic lamina, sparing phosphorylation of rpS6 in the granule cell bodies; (2) local blockade of PI3-kinase blocked somatodendritic phosphorylation of rpS6 while preserving rpS6 phosphorylation in the region of activated synapses. Together, these results suggest that induction of rpS6 phosphorylation at activated synapses is mediated predominately by MAPK/ERK and that generalized somatodendritic activation of rpS6 phosphorylation is medi- ated primarily by PI3-kinase/mTOR (Fig. 9). In what follows, we discuss complications, caveats, and implications.

\section{Induction of rpS6 phosphorylation at active synapses}

Induction of perforant path LTP activates both PI3-kinase (Kelly and Lynch 2000) and MAPK/ERK (Davis et al. 2000; Chotiner et al. 2010). Prolonged HFS leads to dramatic increases in immunostaining for p-ERK throughout the postsynaptic cell, with higher levels of immunostaining in the activated dendritic lamina (Chotiner et al. 2010). The observed differential effects of U0126 
versus wortmannin suggest that the band of increased immunostaining for p-ser235/236 in the region of activated synapses is mediated primarily by MAPK/ERK-dependent signaling (Fig. 9 right side).

MAPK/ERK is thought to activate p-ser235/236 primarily via RSK (Roux et al. 2007). Activation of RSK involves phosphorylation of ser227 in the activation loop of the N-terminal kinase domain (NTKD) (for review, see Nguyen 2008) and the RSK inhibitor, SL0101-1, inhibits the NTKD, blocking phosphorylation of RSK substrates (Smith et al. 2005, 2007). Consistent with the idea that RSK mediates rpS6 phosphorylation at active synapses, local infusion of SL0101-1 partially blocked the band of increased immunostaining for p-ser235/236 in the region of activated synapses. The fact that SL0101-1 did not eliminate the band of increased immunostaining in the activated lamina may be because the RSK blockade is incomplete, a coordinated interaction of RSK with another ERK-dependent substrate is needed, or that kinases other than RSK also contribute.

SL0101-1 also caused modest decreases in immunostaining for p-ser235/236 throughout the somatodendritic compartment suggesting that RSK (and by implication MAPK/ERK) also contributes to $p$-ser235/236 at a distance from the activated synapses. This is consistent with the fact that HFS of the perforant path activates p-ERK throughout the somatodendritic compartment (Chotiner et al. 2010).

\section{Generalized induction of rpS6 phosphorylation throughout the somatodendritic compartment is mediated in part by $\mathrm{mTOR}$}

Our results indicate that both MAPK/ERK and mTOR contribute to generalized induction of $\mathrm{rpS} 6$ phosphorylation throughout the somatodendritic compartment, but mTOR plays a more dominant role, especially for p-ser240/244. This conclusion is supported by the striking result that local delivery of wortmannin selectively blocked phosphorylation of rpS6 in cell bodies and nonactivated dendritic laminae while preserving phosphorylation in the region of activated synapses. Similarly, rapamycin blocked activation of rpS6 phosphorylation throughout the somatodendritic compartment, leaving only a small amount of residual immunostaining for p-ser235/236 in the region of activated synapses. This result is in line with other studies showing residual rpS6 phosphorylation following rapamycin treatment (Pende et al. 2004). However, blockade with LY2940002 was incomplete. It is unknown whether inhibition of PI3-kinase with wortmannin and LY294002 affects downstream mTOR signaling in the same way. One important difference between the two PI3-kinase inhibitors is their mechanism of action. Wortmannin inhibits class I, II, and III isoforms via covalent modification and thus, is an irreversible inhibitor (Powis et al. 1994; Norman et al. 1996). LY294002 affects ATP binding of PI3-kinase and studies with hippocampal slices have shown recovery of function following washout (Sanna et al. 2002). Thus, the partial block by LY294002 may be because the block is reversible.

Infusion of the S6K1 inhibitor, PF4708671, attenuated rpS6 phosphorylation of ser235/236 and ser240/244 throughout the somatodendritic compartment. This is consistent with the interpretation that generalized somatodendritic activation of rpS6 phosphorylation is via mTOR acting in part via S6K1. The fact that blockade was partial may be due to incomplete blockade of S6K1 by PF4708671 or compensation by other kinases, such as RSK, MAP kinase-interacting kinase (MNK) (Panja et al. 2014) or possibly S6K2. A contribution by S6K2 is less likely, however, given evidence that this kinase is restricted to the nucleus (Lee-Fruman et al. 1999).

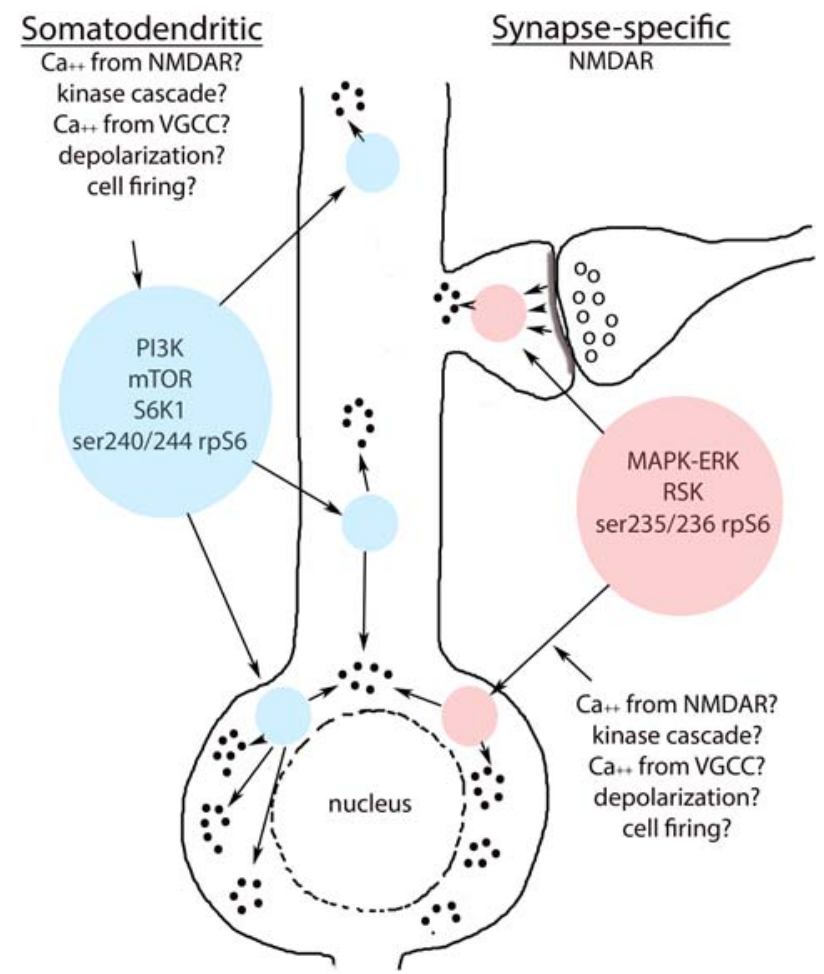

Figure 9. Summary of PI3-kinase/mTOR- and MAPK/ERK-dependent signaling to $\mathrm{rpS} 6$ phosphorylation following synaptic stimulation. Somatodendritic activation of rpS6 phosphorylation at ser240/244 via $\mathrm{PI3}-$ kinase/mTOR-dependent kinases, i.e., S6K1, is the primary mechanism for modifying ribosomes throughout the postsynaptic cell (left side). Synapse-specific phosphorylation of rpS6 at ser235/236 via MAPK/ ERK-dependent kinases, that is, RSK, provides a mechanism for selective modification of ribosomes at activated synapses (right side).

The fact that PF4708671 partially diminished the band of immunostaining at activated synapses adds complexity to an otherwise relatively straightforward story. A possible explanation is that phosphorylation at ser235/236 at active synapses is mediated by MAPK/ERK but with an obligate corequirement for mTOR activation. This is not in accord with the dramatically selective effect of wortmannin, however, which blocks generalized somatodendritic phosphorylation of rpS6 but preserves induction of rpS6 phosphorylation in the region of activated synapses.

\section{Deciphering the role of postsynaptic depolarization and cell firing in rpS6 phosphorylation}

Results with bicuculline and APV indicate that activation of rpS6 phosphorylation is mediated primarily by signals from the synapse via NMDAR activation, and is not due to postsynaptic depolarization, entry of calcium via voltage-gated calcium channels, or massive cell firing. Infusion of bicuculline alone enhances depolarization by blocking GABA receptor-mediated hyperpolarization, which triggers massive cell discharge (multiple population spikes) in response to single pulse stimulation. In this setting, rpS6 phosphorylation is strongly induced. However, rpS6 phosphorylation is completely blocked by co-infusion of APV despite the fact that cell discharge is still greatly enhanced. A caveat, however, is that there were fewer population spikes with co-infusion of bicuculline and APV, which may indicate that NMDA receptor blockade decreases the duration of depolarization. For this reason, a possible contribution of depolarization, calcium entry via voltage- 
gated channels, and massive cell discharge cannot be excluded (Fig. 9).

\section{Possible links between rpS6 phosphorylation and activity-dependent synaptic modifications mediated by MAPK/ERK and mTOR signaling}

Activation of NMDAR-MAPK/ERK-RSK-p-rpS6 locally at activated synapses fits in well with previous evidence implicating MAPK/ ERK in synaptic plasticity. In addition to regulating rpS6 phosphorylation, MAPK/ERK also plays a role in phosphorylation of other translation initiation factors like eukaryotic initiation factor-4E (eIF4E) and 4EBPs (Kelleher et al. 2004b; Kroczynska et al. 2011). Also, RSK forms a complex with 4EBP1 preventing the recruitment of components of eIF4F to the 5' cap structure in its inactive form (Kroczynska et al. 2011), implicating RSK activation in translation initiation. Activation of MAPK/ERK throughout the somatodendritic compartment (Chotiner et al. 2010), is also thought to play a key role in the induction of gene transcription with perforant path LTP (Steward et al. 2007).

Activation of mTOR has also been implicated in late-phase LTP (L-LTP) and other forms of synaptic plasticity. Inhibition of PI3-kinase by intracerebroventricular injection of wortmannin (250 nM) inhibits LTP-associated increases in PI3-kinase phosphorylation diminishing activation of downstream substrates, p-Akt and p-p70S6K, in the dentate gyrus (Kelly and Lynch 2000). In studies of LTP in hippocampal slices, blockade of mTOR with rapamycin reduced L-LTP following HFS but did not block LTP induction (Tang et al. 2002). In another study of LTP in hippocampal slices (Sanna et al. 2002), the PI3-kinase inhibitors, wortmannin, and LY294002 abrogated established LTP, but LTP recovered after washout of the reversible inhibitor, LY294002. Preincubation with LY294002 did not block LTP induction. These data suggest that AKT/mTOR are required for maintenance of LTP after HFS.

Interestingly, there is evidence that both MAPK/ERK and mTOR activation is required for stimulation-induced phosphorylation of translation-related factors (Kelleher et al. 2004b). Overall, studies indicate that there exists a corequirement for MAPK/ERKand mTOR-dependent signaling involved in regulating local protein synthesis. The precise requirement and level of interaction between the pathways needs to be further explored.

Although it was not our goal to assess the effects of the drugs on LTP, our results do provide insights into the relationship between induction of rpS6 phosphorylation and perforant path LTP. For example, although wortmannin blocked rpS6 phosphorylation in cell bodies, it did not impair LTP induction. In some respects, this result has the fewest caveats, because it means that attenuation of rpS6 phosphorylation is not due to diminished synaptic activation during HFS. Also, this result indicates that activation of rpS6 phosphorylation in the activated dendritic lamina is not sufficient for LTP of the population EPSP. LY294002 partially attenuated LTP of the population EPSP, which may account for the partial attenuation of rpS6 phosphorylation in the activated dendritic lamina. U0126 blocked LTP of the population EPSP and blocked rpS6 phosphorylation in the activated dendritic lamina. SL0101-1 attenuated phosphorylation of rpS6 at ser235/236 in the activated dendritic lamina but did not affect rpS6 phosphorylation at ser240/244 and did not block LTP. As with wortmannin, the results with SL0101-1 reveal that rpS6 phosphorylation at ser235/236 in the activated dendritic lamina is not linked to LTP. Finally, PF4708671 attenuated LTP induction and produced partial blockade of rpS6 phosphorylation for both p-ser240/244 and p-ser235/236 in cell bodies and dendrites. It may be that attenuation of LTP induction accounts for the lack of specificity of effects on rpS6 phosphorylation at the different serine residues.
Does phosphorylation of rpS6 regulate mRNA translation? Our findings here document that different signaling pathways regulate rpS6 phosphorylation at active synapses versus the rest of the somatodendritic compartment, but the significance for mRNA translation remains unclear. Our previous study demonstrates that robust induction of rpS6 phosphorylation with HFS of the perforant path is not accompanied by detectable increases in protein synthesis in either granule cell bodies or the dendritic lamina (Pirbhoy et al. 2016). The lack of changes in overall protein synthesis may be because phosphorylation of rpS6 affects translation of only a specific subset of mRNAs and/or shifts translation from one set of mRNAs to another. Alternatively, rpS6 may have some role independent of translation initiation (for review, see Meyuhas 2015). Compelling evidence shows that the positioning of ribosomes in spines is regulated by synaptic activity (Ostroff et al. 2002) and following learning experiences (Ostroff et al. 2017). For example, a recent study reveals that there are increases in polyribosomes within spines in neurons in the amygdala following aversive conditioning. Also, infusion of the cap-dependent initiation inhibitor, 4EGI-1, disrupts training-induced polyribosome positioning and leads to decreases in polyribosomes in dendritic shafts and prevented accumulation of polyribosomes in spine heads whereas polyribosomes at spine bases were preserved (Ostroff et al. 2017). A provocative idea is that phosphorylation of rpS6 via different signaling pathways may play a role in regulating ribosome trafficking in response to synaptic activity. Further studies will be required to explore this possibility.

\section{Materials and Methods}

\section{Animals}

Experimental animals were adult female (150-300 g) SpragueDawley rats from Harlan laboratories (Hsd). Rats were anesthetized with $20 \%$ urethane and positioned in a stereotaxic apparatus as described previously (Steward et al. 1998; Pirbhoy et al. 2016). All experimental procedures were approved by the Institutional Animal Care and Use Committee (IACUC) of the University of California, Irvine.

\section{Acute neurophysiology preparation}

Acute neurophysiological techniques were used to stimulate the medial perforant path projections to the dentate gyrus unilaterally. Projections from the entorhinal cortex to the dentate gyrus are predominately unilateral, so the contralateral side serves as an intra-animal control. A stimulating electrode, an insulated tungsten microelectrode, was stereotaxically positioned in the medial entorhinal cortex ( $4.0 \mathrm{~mm}$ lateral, $1.0 \mathrm{~mm}$ anterior to lambda within a $3.0-4.0 \mathrm{~mm}$ range below the cortical surface). Electrode depth was adjusted to obtain a maximal evoked response in the dentate gyrus with minimal stimulus intensity. Stimulus intensity was set to evoke an $\sim 1.5 \mathrm{mV}$ population spike. The recording electrode, a glass micropipette filled with $0.9 \%$ saline, was positioned in the cell body layer of the dentate gyrus $(3.5 \mathrm{~mm}$ posterior, $1.5-$ $1.7 \mathrm{~mm}$ lateral to bregma and $\sim 3.0 \mathrm{~mm}$ below the cortical surface). The depth of the recording electrode was adjusted to record the positive-going field potential generated by perforant path stimulation.

\section{Experimental procedure}

After positioning electrodes, test stimulation was delivered at a rate of $1 / 10 \mathrm{sec}$ to determine baseline response amplitude. Then highfrequency stimulation was initiated as described below.

\section{High-frequency stimulation (HFS)}

All cases received $60 \mathrm{~min}$ of continuous HFS, which is the standard paradigm used to cause Arc mRNA to localize selectively in 
activated dendritic domains (Steward et al. 1998). Delivery of HFS involved three bouts of ten $400 \mathrm{~Hz}$ trains followed by test stimulation to determine the extent of LTP, then continuing HFS at a rate of $1 / 10 \mathrm{sec}$ for the remaining $60 \mathrm{~min}$.

Immediately after the end of stimulation, rats received a lethal dose of Euthasol $(0.5 \mathrm{~mL})$ or Fatal-plus $(0.5 \mathrm{~mL})$ and were perfused with $4 \%$ paraformaldehyde within 5 min of the last stimulus train.

\section{Local drug infusions}

Stimulating and recording electrodes were positioned as described above, stimulus intensity was adjusted to elicit population spikes of $\sim 1.5 \mathrm{mV}$ in amplitude, and baseline amplitude of the population EPSP and population spike were assessed using a saline-filled recording electrode. The saline-filled microelectrode was then replaced with a microelectrode filled with the designated pharmacological agent (see below), and response amplitude was monitored to confirm placement. Once the drug-filled micropipette electrode was positioned, no test responses were taken for a 15-35-min period. Response amplitude with drug-filled micropipette was then taken for 10-25 min. After recording response amplitude post-drug delivery, HFS was delivered as described above. For U0126, evoked potentials were recorded by connecting leads directly to the metal barrel of a Hamilton microsyringe fitted with a pulled glass micropipette. A total volume of $0.2-0.4 \mu \mathrm{L}(20 \mu \mathrm{M}$ U0126) was injected via Hamilton microsyringe into the dorsal blade of the dentate gyrus before HFS delivery. Post infusion, no test responses were taken for a 35-min period, then a 10-min post infusion baseline was recorded. HFS was then delivered as mentioned above. Of note, in all experiments, stimulus intensity was set to evoke a population spike of $\sim 1.5 \mathrm{mV}$. In some cases, when the saline electrode was switched to place the drug-filled electrode, the population spike dropped below $1.5 \mathrm{mV}$. Thus, values for all drugs are reported for the total number of cases and as a separate value where cases under $1.5 \mathrm{mV}$ are excluded.

\section{Pharmacological agents}

PI3-kinase inhibitor, wortmannin, (4.7 $\mathrm{mM}[2 \mathrm{mg} / \mathrm{mL}]$ in $10 \%$ DMSO in saline; RBI, Cat. W107). PI3-kinase inhibitor,

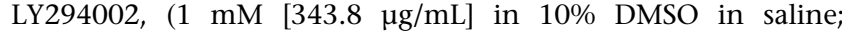
Sigma-Aldrich, Cat. L9908). MEK inhibitor, U0126, (20 $\mu \mathrm{M}$ [8.53 $\mu \mathrm{g} / \mathrm{mL}]$ in $10 \%$ DMSO in saline; Promega, Cat. V112A). mTOR inhibitor, rapamycin $(0.1 \mathrm{mM}(91.417 \mu \mathrm{g} / \mathrm{mL})$ in $10 \%$ DMSO in saline; LC Laboratories, Cat. R5000). RSK inhibitor, SL0101-1, (10 $\mu \mathrm{M}(15.5 \mu \mathrm{g} / \mathrm{mL})$ in $10 \%$ DMSO in saline; AdooQ bioscience, Cat. A1160).

S6K1 inhibitor, PF4708671, $(100 \mu \mathrm{M}(39.0 \mu \mathrm{g} / \mathrm{mL})$ in $10 \%$ DMSO in saline; Tocris, Cat. 4032). GABA(A)-antagonist, bicuculline methiodide $(8 \mathrm{mM}$ [4.1 mg/mL] in saline; RBI, Cat. G-004). NMDA antagonist, APV, $(51 \mathrm{mM}(10 \mathrm{mg} / \mathrm{mL})$ in saline; Tocris, Cat. 0106).

\section{Immunohistochemistry}

Brains were sectioned in the coronal plane on a Vibratome at 40 $\mu \mathrm{m}$ and sections were stored in phosphate buffer $(\mathrm{pH}$ 7.4) before staining. Prior to immunostaining, free-floating sections were placed in microfuge tubes with nanopure water and then the microfuge tubes were placed in boiling water for $5 \mathrm{~min}$ for antigen retrieval. Sections were then treated with $\mathrm{H}_{2} \mathrm{O}_{2}$ to block endogenous peroxidase activity, transferred to $0.01 \%$ Tween in PBS for $15 \mathrm{~min}$, blocked for $1-2 \mathrm{~h}$ at room temperature in TSA blocking buffer and then incubated for 18-20 h in a 1:100 dilution of rpS6 phospho-specific antibodies that recognize phosphorylated ser235/236 (Cell Signaling, catalog \#4858), ser240/244 (Cell Signaling, catalog \#2215) or 1:100 dilution of total rpS6 (Cell Signaling, catalog \#2217). Sections were then incubated in a 1:250 dilution of biotinylated donkey anti-rabbit IgG for $2 \mathrm{~h}$ (Jackson Laboratories, 711-065-152), treated with ABC for $1 \mathrm{~h}$ and stained for $5 \mathrm{~min}$ in DAB. For p-ERK immunostaining, freefloating sections were placed in microfuge tubes with nanopure water and heated to $95^{\circ} \mathrm{C}$ for $5 \mathrm{~min}$. Sections were then washed with TBS and placed in blocking buffer for $2 \mathrm{~h}$ (10\% normal goat serum in TBS) and then incubated for 30-34 h in a 1:200 dilution of polyclonal phosphorylated ERK antibody (Cell Signaling, cata$\log 9101)$. Sections were then incubated in a 1:200 dilution of biotin conjugated goat anti-rabbit IgG secondary in $10 \%$ NGS for $2 \mathrm{~h}$, treated with $\mathrm{ABC}$ for $1 \mathrm{~h}$ and stained for $3 \mathrm{~min}$ in $\mathrm{DAB}$. After immunostaining, sections were mounted on $0.5 \%$ gelatin subbed slides. Slides were dehydrated through washes of graded ethanol, cleared in three changes of xylene and coverslipped with DPX.

\section{Image quantification}

Optical density (OD) across the granule cell layer and molecular layers of the dentate gyrus was quantified using NIH ImageJ as described previously (Farris et al. 2014). Images were taken at $20 \times$ at the same exposure. A region of interest (ROI) line was aligned perpendicular to the cell body layer extending through the dendritic laminae, and OD was measured at 20-um intervals. The OD at each level was averaged across the total number of line measurements per image to obtain an average value along the ROI line for each section ( $\sim 19$ measurements). Overall, the average ROI line values per case were then averaged across rats to generate an "average optical density versus distance" graph where $N=$ number of rats. Values are presented as mean \pm SEM. For the assessment of changes in immunostaining per region (granule cell layer (GCL), inner molecular layer (IML), middle molecular layer (MML), outer molecular layer (OML)), values were obtained as described above except that OD values were taken from each corresponding region.

\section{Statistical analysis}

All statistical analyses were done using Prism (GraphPad Software, San Diego, USA). For all analyses, " $N$ " = number of animals.

\section{Competing interest statement}

O.S. holds interests in the company called "Axonis," which holds patents on interventions targeting PTEN to enable axon regeneration following injury. P.S.P. declares no competing financial interests.

\section{Acknowledgments}

This study was supported by National Institutes of Health (NIH) grant NS12333 (O.S.); P.S.P. was the recipient of fellowship support from NIH MBRS-IMSD GM055246, NIH 5T32 NS045540, and NIH NINDS F31 NS083349. Thank you to Kelly Yee and Jamie Mizufuka for technical assistance.

\section{References}

Anjum R, Blenis J. 2008. The RSK family of kinases: emerging roles in cellular signalling. Nat Rev Mol Cell Biol 9: 747-758.

Arcaro A, Wymann MP. 1993. Wortmannin is a potent phosphatidylinositol 3-kinase inhibitor: the role of phosphatidylinositol 3,4,5-trisphosphate in neutrophil responses. Biochem J 296(Pt 2): 297-301.

Biever A, Puighermanal E, Nishi A, David A, Panciatici C, Longueville S, Xirodimas D, Gangarossa G, Meyuhas O, Hervé D, et al. 2015. PKA-dependent phosphorylation of ribosomal protein S6 does not correlate with translation efficiency in striatonigral and striatopallidal medium-sized spiny neurons. J Neurosci 35: 4113-4130.

Chotiner JK, Nielson J, Farris S, Lewandowski G, Huang F, Banos K, de Leon R, Steward O. 2010. Assessment of the role of MAP kinase in mediating activity-dependent transcriptional activation of the immediate early gene Arc/Arg3.1 in the dentate gyrus in vivo. Learn Mem 17: 117-129.

Costa-Mattioli M, Sossin WS, Klann E, Sonenberg N. 2009. Translational control of long-lasting synaptic plasticity and memory. Neuron 61: 10-26.

Davis S, Vanhoutte P, Pagès C, Caboche J, Laroche S. 2000. The MAPK/ERK cascade targets both Elk-1 and cAMP response element-binding protein to control long-term potentiation-dependent gene expression in the dentate gyrus in vivo. J Neurosci 20: 4563-4572. 
Dufner A, Thomas G. 1999. Ribosomal S6 kinase signaling and the control of translation. Exp Cell Res 253: 100-109.

Farris S, Lewandowski G, Cox CD, Steward O. 2014. Selective localization of arc mRNA in dendrites involves activity- and translation-dependent mRNA degradation. J Neurosci 34: 4481-4493.

Favata MF, Horiuchi KY, Manos EJ, Daulerio AJ, Stradley DA, Feeser WS, Van Dyk DE, Pitts WJ, Earl RA, Hobbs F, et al. 1998. Identification of a novel inhibitor of mitogen-activated protein kinase kinase. J Biol Chem 273: 18623-18632.

Frödin M, Jensen CJ, Merienne K, Gammeltoft S. 2000. A phosphoserine-regulated docking site in the protein kinase RSK2 that recruits and activates PDK1. EMBO J 19: 2924-2934.

Gangarossa G, Valjent E. 2012. Regulation of the ERK pathway in the dentate gyrus by in vivo dopamine D1 receptor stimulation requires glutamatergic transmission. Neuropharmacology 63: 1107-1117.

Gobert D, Topolnik L, Azzi M, Huang L, Badeaux F, Desgroseillers L, Sossin WS, Lacaille JC. 2008. Forskolin induction of late-LTP and up-regulation of $5^{\prime}$ TOP mRNAs translation via mTOR, ERK, and PI3K in hippocampal pyramidal cells. J Neurochem 106: 1160-1174.

Gong R, Park CS, Abbassi NR, Tang S-J. 2006. Roles of glutamate receptors and the mammalian target of rapamycin (mTOR) signaling pathway in activity-dependent dendritic protein synthesis in hippocampal neurons. J Biol Chem 281: 18802-18815.

Huang F, Chotiner JK, Steward O. 2007. Actin polymerization and ERK phosphorylation are required for Arc/Arg3.1 mRNA targeting to activated synaptic sites on dendrites. J Neurosci 27: 9054-9067.

Jefferies HB, Reinhard C, Kozma SC, Thomas G. 1994. Rapamycin selectively represses translation of the "polypyrimidine tract" mRNA family. Proc Natl Acad Sci 91: 4441-4445.

Jensen CJ, Buch MB, Krag TO, Hemmings BA, Gammeltoft S, Frödin M. 1999. 90-kDa ribosomal S6 kinase is phosphorylated and activated by 3-phosphoinositide-dependent protein kinase-1. J Biol Chem 274: 27168-27176.

Jin SX, Arai J, Tian X, Kumar-Singh R, Feig LA. 2013. Acquisition of contextual discrimination involves the appearance of a RAS-GRF1/p38 mitogen-activated protein (MAP) kinase-mediated signaling pathway that promotes long term potentiation (LTP). J Biol Chem 288: 21703-21713.

Kandel ER. 2001. The molecular biology of memory storage: a dialogue between genes and synapses. Science 294: 1030-1038.

Kelleher RJ III, Govindarajan A, Tonegawa S. 2004a. Translational regulatory mechanisms in persistent forms of synaptic plasticity. Neuron 44: 59-73.

Kelleher RJ III, Govindarajan A, Jung H-Y, Kang H, Tonegawa S. 2004b. Translational control by MAPK signaling in long-term synaptic plasticity and memory. Cell 116: $467-479$.

Kelly A, Lynch MA. 2000. Long-term potentiation in dentate gyrus of the rat is inhibited by the phosphoinositide 3-kinase inhibitor, wortmannin. Neuropharmacology 39: 643-651.

Kroczynska B, Joshi S, Eklund EA, Verma A, Kotenko SV, Fish EN, Platanias LC. 2011. Regulatory effects of ribosomal S6 kinase 1 (RSK1) in IFNlambda signaling. J Biol Chem 286: 1147-1156.

Lee-Fruman KK, Kuo CJ, Lippincott J, Terada N, Blenis J. 1999. Characterization of $56 \mathrm{~K} 2$, a novel kinase homologous to S6K1. Oncogene 18: $5108-5114$.

Meyuhas O. 2008. Chapter 1 Physiological Roles of Ribosomal Protein S6: One of Its Kind. In International Review of Cell and Molecular Biology, Vol. 268, pp. 1-37. Elsevier.

Meyuhas O. 2015. Ribosomal protein S6 phosphorylation: four decades of research. Int Rev Cell Mol Biol 320: 41-73.

Nguyen TL. 2008. Targeting RSK: an overview of small molecule inhibitors. Anticancer Agents Med Chem 8: 710-716.

Nguyen PV, Kandel ER. 1996. A macromolecular synthesis-dependent late phase of long-term potentiation requiring cAMP in the medial perforant pathway of rat hippocampal slices. J Neurosci 16: 3189-3198.

Norman BH, Shih C, Toth JE, Ray JE, Dodge JA, Johnson DW, Rutherford PG, Schultz RM, Worzalla JF, Vlahos CJ. 1996. Studies on the mechanism of phosphatidylinositol 3-kinase inhibition by wortmannin and related analogs. J Med Chem 39: 1106-1111.

Ostroff LE, Fiala JC, Allwardt B, Harris KM. 2002. Polyribosomes redistribute from dendritic shafts into spines with enlarged synapses during LTP in developing rat hippocampal slices. Neuron 35: 535-545.

Ostroff LE, Botsford B, Gindina S, Cowansage KK, LeDoux JE, Klann E, Hoeffer C. 2017. Accumulation of polyribosomes in dendritic spine heads, but not bases and necks, during memory consolidation depends on cap-dependent translation initiation. J Neurosci 37: 1862-1872.

Panja D, Dagyte G, Bidinosti M, Wibrand K, Kristiansen AM, Sonenberg N, Bramham CR. 2009. Novel translational control in Arc-dependent long term potentiation consolidation in vivo. J Biol Chem 284: 31498-31511.

Panja D, Kenney JW, D'Andrea L, Zalfa F, Vedeler A, Wibrand K, Fukunaga R, Bagni C, Proud CG, Bramham CR. 2014. Two-stage translational control of dentate gyrus LTP consolidation is mediated by sustained BDNF-TrkB signaling to MNK. Cell Rep 9: 1430-1445.

Park IH, Bachmann R, Shirazi H, Chen J. 2002. Regulation of ribosomal S6 kinase 2 by mammalian target of rapamycin. J Biol Chem 277: 31423-31429.

Pearce LR, Alton GR, Richter DT, Kath JC, Lingardo L, Chapman J, Hwang C, Alessi DR. 2010. Characterization of PF-4708671, a novel and highly specific inhibitor of p70 ribosomal S6 kinase (S6K1). Biochem J 431: 245-255.

Pende M, Um SH, Mieulet V, Sticker M, Goss VL, Mestan J, Mueller M, Fumagalli S, Kozma SC, Thomas G. 2004. S6K1-/-/S6K2-/- mice exhibit perinatal lethality and rapamycin-sensitive $5^{\prime}$-terminal oligopyrimidine mRNA translation and reveal a mitogen-activated protein kinase-dependent S6 kinase pathway. Mol Cell Biol 24: 3112-3124

Pirbhoy PS, Farris S, Steward O. 2016. Synaptic activation of ribosomal protein S6 phosphorylation occurs locally in activated dendritic domains. Learn Mem 23: 255-269.

Powis G, Bonjouklian R, Berggren MM, Gallegos A, Abraham R, Ashendel C, Zalkow L, Matter WF, Dodge J, Grindey G, et al. 1994. Wortmannin, a potent and selective inhibitor of phosphatidylinositol-3-kinase. Cancer Res 54: $2419-2423$.

Roux PP, Shahbazian D, Vu H, Holz MK, Cohen MS, Taunton J, Sonenberg N, Blenis J. 2007. RAS/ERK signaling promotes site-specific ribosomal protein S6 phosphorylation via RSK and stimulates cap-dependent translation. J Biol Chem 282: 14056-14064.

Sanna PP, Cammalleri M, Berton F, Simpson C, Lutjens R, Bloom FE, Francesconi W. 2002. Phosphatidylinositol 3-kinase is required for the expression but not for the induction or the maintenance of long-term potentiation in the hippocampal CA1 region. J Neurosci 22: 3359-3365.

Shahbazian D, Roux PP, Mieulet V, Cohen MS, Raught B, Taunton J, Hershey JWB, Blenis J, Pende M, Sonenberg N. 2006. The mTOR/PI3K and MAPK pathways converge on eIF4B to control its phosphorylation and activity. EMBO I 25: 2781-2791.

Smith JA, Poteet-Smith CE, Xu Y, Errington TM, Hecht SM, Lannigan DA. 2005. Identification of the first specific inhibitor of p90 ribosomal S6 kinase (RSK) reveals an unexpected role for RSK in cancer cell proliferation. Cancer Res 65: 1027-1034.

Smith JA, Maloney DJ, Hecht SM, Lannigan DA. 2007. Structural basis for the activity of the RSK-specific inhibitor, SL0101. Bioorg Med Chem 15: 5018-5034.

Steward O, Worley PF. 2001. Selective targeting of newly synthesized Arc mRNA to active synapses requires NMDA receptor activation. Neuron 30: 227-240.

Steward O, Tomasulo R, Levy WB. 1990. Blockade of inhibition in a pathway with dual excitatory and inhibitory action unmasks a capability for LTP that is otherwise not expressed. Brain Res 516: 292-300.

Steward O, Wallace CS, Lyford GL, Worley PF. 1998. Synaptic activation causes the mRNA for the IEG Arc to localize selectively near activated postsynaptic sites on dendrites. Neuron 21: 741-751.

Steward O, Huang F, Guzowski JF. 2007. A form of perforant path LTP can occur without ERK1/2 phosphorylation or immediate early gene induction. Learn Mem 14: 433-445.

Tang SJ, Reis G, Kang H, Gingras AC, Sonenberg N, Schuman EM. 2002. A rapamycin-sensitive signaling pathway contributes to long-term synaptic plasticity in the hippocampus. Proc Natl Acad Sci 99: 467-472.

Thoreen CC, Chantranupong L, Keys HR, Wang T, Gray NS, Sabatini DM. 2012. A unifying model for mTORC1-mediated regulation of mRNA translation. Nature 485: 109-113.

Tsokas P, Grace EA, Chan P, Ma T, Sealfon SC, Iyengar R, Landau EM, Blitzer RD. 2005. Local protein synthesis mediates a rapid increase in dendritic elongation factor $1 \mathrm{~A}$ after induction of late long-term potentiation. J Neurosci 25: 5833-5843.

Vlahos CJ, Matter WF, Hui KY, Brown RF. 1994. A specific inhibitor of phosphatidylinositol 3-kinase,

2-(4-morpholinyl)-8-phenyl-4H-1-benzopyran-4-one (LY294002). J Biol Chem 269: 5241-5248.

Wang H, Peng RY. 2016. Basic roles of key molecules connected with NMDAR signaling pathway on regulating learning and memory and synaptic plasticity. Mil Med Res 3: 26.

Wang L, Gout I, Proud CG. 2001a. Cross-talk between the ERK and p70 S6 kinase (S6K) signaling pathways. MEK-dependent activation of S6K2 in cardiomyocytes. J Biol Chem 276: 32670-32677.

Wang X, Li W, Williams M, Terada N, Alessi DR, Proud CG. 2001b. Regulation of elongation factor 2 kinase by p90RSK1 and p70 S6 kinase. EMBO J 20: 4370-4379.

Received January 4, 2017; accepted in revised form May 18, 2017. 

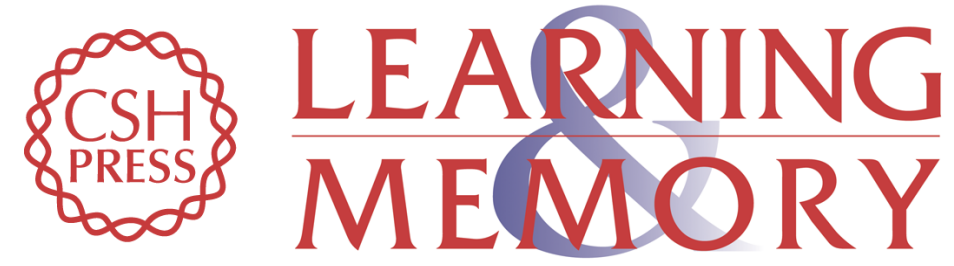

\section{Synaptically driven phosphorylation of ribosomal protein $\mathbf{S 6}$ is differentially regulated at active synapses versus dendrites and cell bodies by MAPK and PI3K/mTOR signaling pathways}

Patricia Salgado Pirbhoy, Shannon Farris and Oswald Steward

Learn. Mem. 2017, 24:

Access the most recent version at doi:10.1101/lm.044974.117

\section{Supplemental http://learnmem.cshlp.org/content/suppl/2017/07/11/24.8.341.DC1 Material \\ References This article cites 53 articles, 32 of which can be accessed free at: http://learnmem.cshlp.org/content/24/8/341.full.html\#ref-list-1 \\ Creative This article is distributed exclusively by Cold Spring Harbor Laboratory Press for the Commons first 12 months after the full-issue publication date (see \\ License http://learnmem.cshlp.org/site/misc/terms.xhtml). After 12 months, it is available under a Creative Commons License (Attribution-NonCommercial 4.0 International), as described at http://creativecommons.org/licenses/by-nc/4.0/. \\ Email Alerting Receive free email alerts when new articles cite this article - sign up in the box at the Service top right corner of the article or click here.}

